\title{
A REVIEW OF OPTICAL INTERFEROMETRY TECHNIQUES FOR VOC DETECTION
}

\author{
Sulaiman Khan ${ }^{1,2,3}$, Stéphane Le Calvé, ${ }^{2,3}$, David Newport ${ }^{1 *}$ \\ ${ }^{1}$ School of Engineering, Bernal Institute, University of Limerick, Limerick, Ireland. \\ sulaiman.khan@ul.ie,david.newport@ul.ie
}

${ }^{2}$ University of Strasbourg, Institute of Chemistry and Processes for Energy, Environment and Health (ICPEES), Group of Atmospheric Physical Chemistry, Strasbourg France.

slecalve@unistra.fr

${ }^{3}$ In'Air Solutions, Strasbourg France. 


\begin{abstract}
Exposure to volatile organic compounds (VOCs) is widely associated with adverse health effects. Detection and monitoring of VOCs are important for maintaining safe and healthy industrial and domestic environments. Interferometry is a highly-sensitive optical measurement technique that has been widely applied to a vast range of physical parameters from the speed of light to temperature and has also been used to detect VOCs at the sub-ppm range. Owing to the vast range of interferometer arrangements and processing techniques, this review assesses the different approaches adopted in detecting VOCs. Different interferometry arrangements including the Fabry-Perot interferometry, Sagnac interferometry and Mach-Zehnder interferometry are reviewed for VOC detection, including the different sensing films and materials employed. We present the basis of each technique, applications and limitations. The different interferometry techniques are summarized by comparing the sensitivity, limit of detection, linearity, response time and the challenges of current interferometry techniques. Lastly, prospects to realize a miniaturized, high-sensitive and multiplex interferometric sensors based on the recent technology are suggested.
\end{abstract}

\title{
Key Words
}

Gas sensor; optical gas sensor; Fabry-Perot interferometer; Sagnac interferometry; Mach-Zehnder interferometer; Zeolite. 


\section{Introduction}

VOCs are organic compounds that have a high vapour pressure at room temperature, i.e. they readily evaporate into a gaseous phase at room temperature. The United States Environmental Protection Agency (EPA) defines VOCs as "organic chemical compounds whose composition makes it possible for them to evaporate under normal indoor atmospheric conditions of temperature and pressure" [1]. The EU uses the boiling point for the definition with a VOC being "any organic compound having an initial boiling point less than or equal to $25^{\circ} \mathrm{C}$ measured at standard atmospheric pressure of $101.3 \mathrm{kPa}$ " [2]. Common VOCs are acetaldehyde, acetone, benzene, carbon tetrachloride, ethyl acetate, heptane, hexane, isopropyl alcohol, formaldehyde, naphthalene, styrene, toluene and xylenes [3,4]. Most VOCs, such as the aromatic compounds, alcohols, ketones and aldehyde are toxic. Benzene, Toluene, Ethylbenzene and Xylene (BTEX) are aromatic hydrocarbons, considered as some of the most hazardous pollutants among VOCs.

VOCs can be found in both indoor and outdoor environments. Outdoors, the common sources are emission from automobiles, vegetation, petroleum products and incomplete fuel combustion $[5,6]$. The natural sources are mainly emissions from terrestrial and ocean sources [7]. BTEX levels are typically greater in indoor environments [8]. In public places, the sources of BTEX are coal burning, cigarette smoking, combustion and cleaning products, laser printing, floor adhesives, paint, wood panelling and traffic emissions [9] [10] [11].

Exposure to BTEX and other VOCs is one of the reasons for sick building syndrome [12]. Benzene is particularly toxic and carcinogenic [16.17]. Acute occupational exposure to benzene can cause narcosis, headache, dizziness, drowsiness, confusion, tremor and loss of consciousness [13].[14][15]. The International Agency for Research on Cancer has classified benzene as carcinogenic to humans [16]. Exposure to toluene can affect the central nervous system, liver, kidney and skin [17]. Exposure to xylene at a low level can cause fatigue, tremor, nervous system, respiratory, kidney and cardiovascularrelated problems [18]. Inhalation of acetone is associated with headache, dizziness and dermatitis. The symptoms of cyclohexane exposure include irritation of respiratory tract, skin and eyes. Formaldehyde is toxic and allergenic [19]. It is widely used in industry due to its high reactivity and low cost. Highlevel exposure can cause nasopharyngeal cancer and can damage cells and tissues [20]. The World Health Organisation has set its maximum exposure limit of $100 \mu \mathrm{g} / \mathrm{m}^{3}(81.4 \mathrm{ppb})$ averaged over $30 \mathrm{~min}$ [21]. Methanol exposure can cause nausea, abdominal pain, shortness of breath and dizziness [17].

Different developed countries and organization have set increasingly more stringent legislation and regulation for exposure limits to harmful VOCs. The EU adopted a maximum exposure limit of $5 \mu \mathrm{g} / \mathrm{m}^{3}$ (1.6ppb) for benzene effective from 2010 [22]. Different organizations, for instance, National Institute 
of Occupational Safety and Health (NIOSH) and Occupational Safety and Health Administration (OSHA) have established exposure limits to different VOCs as summarized in Table 1 [23]. The recommended exposure threshold values range from sub-ppb (0.6 ppb for benzene) to $1000 \mathrm{ppm}$ for ethanol.

Table 1: The different exposure limits recommended by various organizations

\begin{tabular}{|c|c|c|c|c|}
\hline VOCs & $\begin{array}{c}\text { NIOSH- } \\
\text { Recommended } \\
\text { Exposure Limit } \\
(\mathrm{ppm})\end{array}$ & $\begin{array}{c}\text { OSHA - } \\
\text { Permissible } \\
\text { Exposure Limit } \\
(\mathrm{ppm})\end{array}$ & $\begin{array}{c}\text { ACGIH- } \\
\text { Threshold Limit } \\
\text { Value }^{\mathrm{c}} \\
(\mathrm{ppm})\end{array}$ & $\begin{array}{c}\text { ANSES (VGAI) - } \\
\text { Long exposure }^{\mathrm{d}} \\
(\mathrm{ppm})\end{array}$ \\
\hline Benzene & 0.1 & 1 & 0.5 & 0.0006 \\
\hline Toluene & 100 & 200 & 20 & 5.31 \\
\hline Ethylbenzene & 10 & 10 & 10 & 0.345 \\
\hline Xylene(m-,o-,p- $)$ & 100 & 100 & 100 & - \\
\hline Formaldehyde & 0.016 & 0.75 & 0.3 & - \\
\hline Acetone & 250 & 1000 & 250 & - \\
\hline Ethanol & 1000 & 1000 & 1000 & - \\
\hline Methanol & 200 & 200 & 250 & - \\
\hline Isopropanol & 400 & 400 & 200 & \\
\hline
\end{tabular}

Detection of VOCs at trace level requires a highly sensitive and accurate sensing method. Different sensing techniques have been reported to detect and monitor VOCs, for instance Photo-ionization detectors (PID) [24], electrochemical gas sensors [25], micro gas chromatography ( $\mu$-GC) [26] , piezoelectric-based gas sensors i.e. surface acoustic wave [27], quartz crystal microbalances [28], and tuning fork [29], gravimetric-based gas sensors [30], metal-oxide semiconductor (MOS) gas sensors [31] and optical sensor such as colorimetric gas sensors [32], non-dispersive infrared gas sensors[29] and UV spectrophotometry gas sensors [33]. Each technique has its advantages and shortcomings depending upon the nature of molecules and the environment. MOS sensors usually operate at high temperature with high sensitivity to external humidity and gases like $\mathrm{CO}_{2}$. Electrochemical sensors have

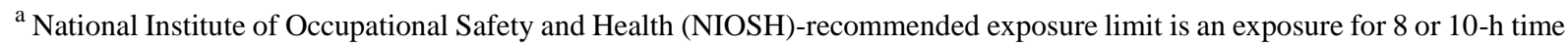
weighted-average.

${ }^{\mathrm{b}}$ Occupational Safety and Health Administration (OSHA) permissible exposure limit are expressed as a time-weighted average; the concentration of a substance to which most workers can be exposed without adverse effect averaged over a normal 8-h workday or a 40 -h workweek.

${ }^{c}$ American Conference of Governmental and Industrial Hygienists (ACGIH) threshold limit value are expressed as a timeweighted average; the concentration of a substance to which most workers can be exposed without adverse effects.

${ }^{\mathrm{d}}$ National Agency for Food Safety, Environment and Labor (ANSES) Interior Air Quality Guide Values (VGAI) France.
} 
major issues of ageing and zero drift. PIDs have disadvantages of selectivity, cost, and complex electronics. Piezoelectric-based sensors show large measurement-noise and have sensitivity to humidity and temperature. The advantages and disadvantages of different techniques are summarized in Table 2

Table 2. Pros and Cons of different gas sensing techniques.

\begin{tabular}{|c|c|c|}
\hline $\begin{array}{l}\text { Gas detection } \\
\text { Technique }\end{array}$ & Advantages & Disadvantages \\
\hline $\begin{array}{l}\text { Metal Oxide } \\
\text { Semiconductor }\end{array}$ & $\begin{array}{l}\text { Low cost. } \\
\text { Acceptable lifetime. } \\
\text { Easily to integrate. }\end{array}$ & $\begin{array}{l}\text { Relative low selectivity and sensitivity. } \\
\text { High operating temperature. } \\
\text { Zero-drift and ageing effect. } \\
\text { Sensitive to external temperature and humidity. }\end{array}$ \\
\hline Photoionization & $\begin{array}{l}\text { Excellent sensitivity to } \\
\text { aromatics. } \\
\text { Quick response. } \\
\text { Portable. }\end{array}$ & $\begin{array}{l}\text { Limited selectivity, all the gases with IP equal or } \\
\text { lower the photon could be detected. } \\
\text { Complex electronics. } \\
\text { Cost. }\end{array}$ \\
\hline Electro-Chemical & $\begin{array}{l}\text { Relative sensitive. } \\
\text { Reliable. } \\
\text { Lower cost }\end{array}$ & $\begin{array}{l}\text { Zero drift. } \\
\text { Short life and ageing. }\end{array}$ \\
\hline Piezoelectric & $\begin{array}{l}\text { Good sensitivity. } \\
\text { Portable. } \\
\text { Good dynamic range. }\end{array}$ & $\begin{array}{l}\text { Large measurement noise, sensitive to external } \\
\text { temperature and humidity. } \\
\text { Weak selectivity. } \\
\text { Zero drift and cross-reactivity. }\end{array}$ \\
\hline
\end{tabular}

During the last few decades, tremendous advancements have been observed in the area of optical sensors for gas detection applications. Optical gas sensors can detect gas molecules with high sensitivity and selectivity. They are non-destructive, have quick response times and do not generally suffer from drift. They have little cross-response to other gases, are inherently reliable and have high specificity [34]. Various types of optical detection are available with direct spectrometry, and reagent/film mediated optical sensor are the common types of sensors used for sensing applications [35][36]. In film/reagent mediated sensing system, a change in the optical response of an intermediate agent is used to quantify the analytes absorbed/adsorbed on the sensing surface and then to deduce the gas concentrations once calibration is performed [35]. Interferometry applied gas detection can be considered as a film-mediated optical sensing method because it is the variation in the optical path length of the sensing film which is monitored.

Interferometry is an important investigative and detection technique in the fields of astronomy, fiber optics, engineering metrology, optical metrology, oceanography, seismology, spectroscopy, biosensing, surface profiling and chemical sensing [37][38][39]. There is a wide range of interferometric configurations and processing techniques that have been deployed for VOCs detection. This paper aims at establishing a detailed review of interferometry techniques used for VOCs detection. The different designs of interferometry for VOCs detection will be discussed and compared in terms of sensor design and analytical performances including linearity, sensitivity and time response. Pros and cons of the 
techniques applied as well as the different sensing films and materials used will be discussed. Points for improvement and possible miniaturization will be considered in perspective.

\section{Interferometry}

Optical interferometry is a well-known investigative technique applied to a number of applications for highly precise measurements. Examples range from Michelson and Morley's aether drift experiment to the extraordinary sensitivity of the modern gravitational-wave detector [40]. During the last few decades, interferometry has been applied to several applications in nano-science and technology for highly sensitive measurements due to being in-situ, non-contact and non-destructive. Recent advancements in computation, data acquisition and data analysis have made it possible to achieve a highly-precise and sensitive measurement using interferometry. Fringe analysis and phase retrieval processes became faster with the use of digital computers and further enhancement in future is foreseen [41][42]. For instance, the displacement sensitivity of pico-meter has been demonstrated using interferometry [43][44]. Interferometry has also been applied for highly precise measurement of temperature [45], pressure [46], gas concentrations [47], growth rate in crystallization [48], refractive index of materials [49], acoustic field [50], surface profile [51], vibration [52] and bio-sensing [53][54], for different applications.

Generally, for sensing application, two-beam amplitude-division interferometry is employed [55]. The working principle of two-beam amplitude-division interferometry is that two light beams of the same frequency, constant phase difference and same direction are recombined to form an interference pattern, which can be expressed as,

$$
I=I_{1}+I_{2}+2 \sqrt{I_{1} I_{2}} \cos \phi
$$

Where $I_{I}$ and $I_{2}$ are the beam intensities and $\phi$ is the phase difference between the two beams, which is given by,

$$
\phi=\frac{N \pi n L}{\lambda}
$$

Where $n$ and $L$ is the refractive index and the length over which the phase change occurs respectively. $N$ value varies with technique. For FP interferometer $\mathrm{N}=4$ and Mach-Zehnder Interferometer $\mathrm{N}=2$. Interferometry quantifies the phase changes induced by the measurand, i.e. temperature, pressure, strain, concentration and refractive index. The objective of interferometry is to measure the phase difference and relate it with the measurand.

Interferometry for VOC detection assesses changes in sensing materials, typically films. The sensing film is usually a polymer or microporous-silicates, selected according to the desired target molecules. When a VOC interacts with the gas sensing film, it changes volume (i.e. thickness) and/or optical 
properties (i.e. refractive index) of the film due to absorption/adsorption. These perturbations change the effective optical path length, which leads to a quantifiable phase shift, as shown in figure 1. By demodulating the phase shift, the concentration of VOCs can be inferred.

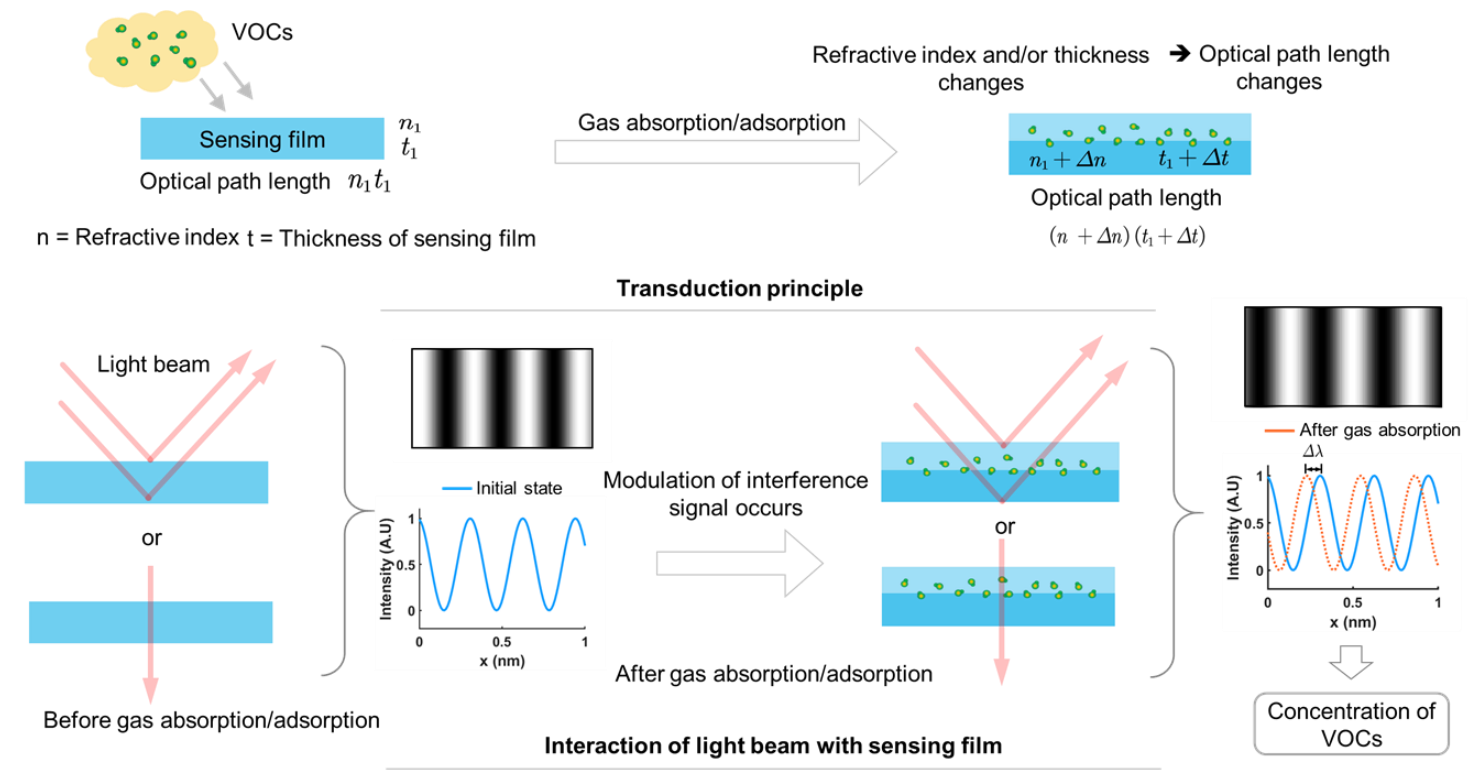

Figure 1. Mechanism of interferometry for gas detection. The sensing film is exposed to VOCs which changes its thickness and refractive index resulting in a shift of wavelength.

There are a number of optical configurations for interferometry. The common interferometry techniques employed for VOC detection are the Fabry-Perot, Sagnac, Mach-Zehnder and Pohl interferometers.

\subsection{Fabry-Perot interferometer}

The Fabry-Perot (FP) interferometer, also called the Fabry-Perot etalon, is composed of two mirrors of reflectance $R_{l}$ and $R_{2}$ separated by the cavity of length $L$, as shown in Figure 2(A). The FP interferometer works as a reflective device and is approximately equivalent to a two-beam interferometer. It is very sensitive to perturbation that changes the optical path length between the two mirrors. The FP interferometer is compact, has a fast response and is readily integrated [56]. It has been applied to several applications such as temperature, pressure, humidity, stress and strain, vibration, bio-sensing, gas detection, magnetic fields, current and airflow measurement [57].

(A)

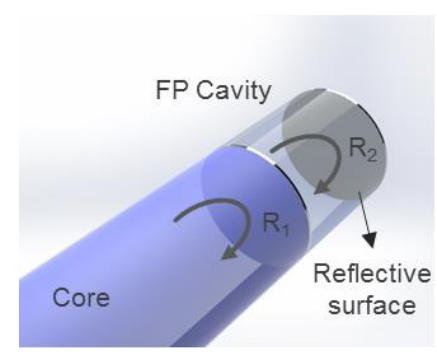

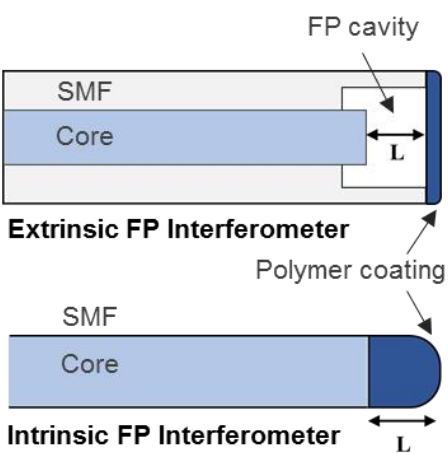


(B)

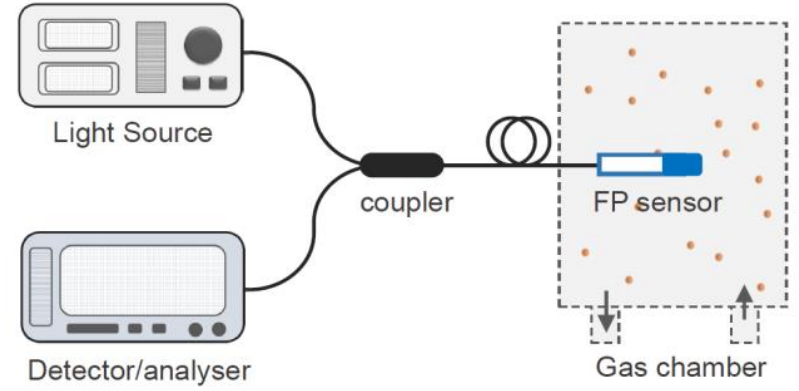

Figure 2. (A) FP interferometer having reflective surfaces with reflectivity of $R_{1}$ and $R_{2}$, respectively. Examples of intrinsic and extrinsic FP interferometers. (B) The experimental setup employed for detection of VOCs using FP interferometer.

FP interferometer can be categorized into either intrinsic or extrinsic. In both types, a fiber is coupled to transport light from the emitter to the interferometer and then to a photodetector. In an intrinsic FP interferometer, the two mirrors are separated by the length of the fiber, and the measurand interacts with light propagating in the fiber to change the optical path length. In an extrinsic interferometer, the two mirrors are separated by an air gap or other material. The measurand changes the optical path length in a medium other than the fiber. Examples of intrinsic and extrinsic FP interferometers are given in Figure 2(A).

The reflectance and transmittance for low-finesse FP is given by [58],

$$
R_{F P}=\frac{R_{1}+R_{2}+2 \sqrt{R_{1} R_{2}} \cos \phi}{1+R_{1} R_{2}+2 \sqrt{R_{1} R_{2}} \cos \phi}
$$

$R_{F P}$ is the ratio of power reflected by FP interferometer to the incident power, where $\phi$ is a phase shift in the interferometer which is represented as,

$$
\phi=\frac{4 \pi n L}{\lambda}
$$

Where $L$ is the length of the FP cavity and $n$ is the refractive index of the FP cavity. For resonant wavelength, the reflection spectrum satisfies the condition,

$$
\frac{4 \pi n L}{\lambda}=2 k \pi
$$

Where $k=1,2,3, \ldots$ and $n L$ is the optical path length of the FP cavity. The dip wavelength $\lambda_{d i p}$ is given by

$$
\lambda_{d i p}=\frac{2 n L}{k}
$$

VOCs concentration can be measured by monitoring the wavelength shift of the reflective resonant spectrum. The experimental setup used for gas sensing consists of a light source and detector, fibercoupler and gas enclosure, where the FP sensor is exposed to gas molecules, as shown in figure 2(B). 


\subsection{Sagnac interferometer (SI)}

The Sagnac interferometer is used in filtering, communications and sensor applications due to its simple design, ease of fabrication and lower susceptibility to external noise [59]. It has been applied for gas detection [47], pressure[59], temperature[60], humidity[61], and strain measurements [62]. The Sagnac interferometer is usually applied in a ring configuration, or fiber loop mirror for gas sensing, as shown in Figure 3(B). A fiber coupler split the input light in two and then recombines the two counterpropagating beams. A section of birefringent fiber (Polarization-Maintaining Fiber (PMT)) is inserted in the loop which causes interference between the two counter-propagating waves when it interacts with measurand as shown in figure 3(A). The output of the transmitted intensity can be expressed as [63],

$$
I_{S G}=\frac{1}{2}\left(1-\cos \frac{2 \pi B L}{\lambda}\right)
$$

(A)

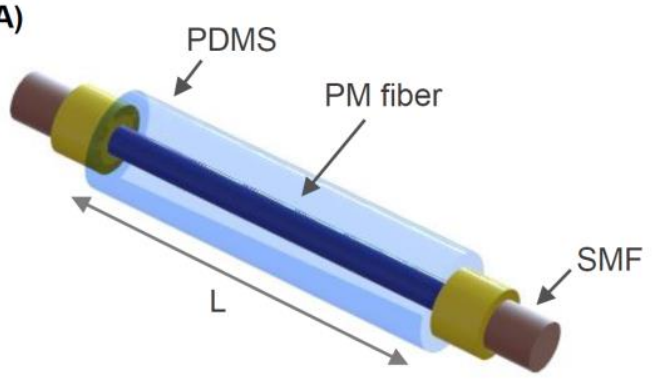

(B)

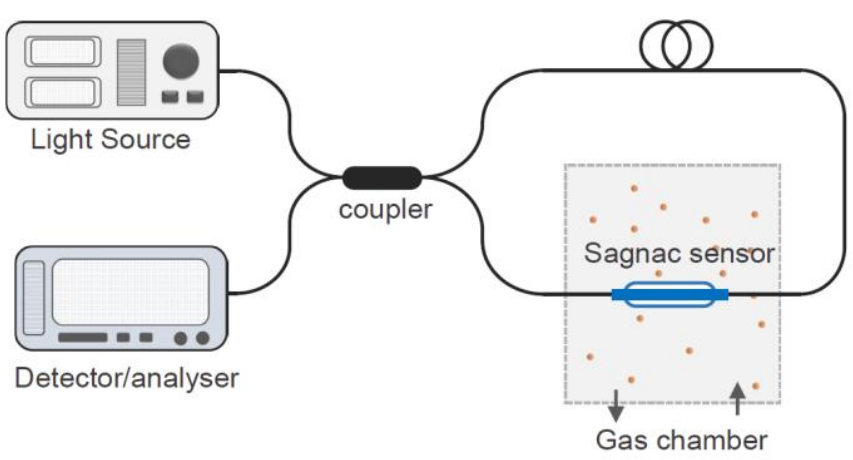

Figure 3. (A) Schematic of Sagnac interferometer. A Sagnac interferometer is constructed by employing a Polarization Maintaining (PM) fiber in the fiber loop. (B) Schematics of the experimental setup used for VOC detection using Sagnac interferometer.

Where $L$ is the length of the birefringent fiber, $B$ is the refractive index difference between the fast axis and slow axis of birefringent fiber, $\lambda$ is the wavelength of light beam in free space. When the phase difference satisfies the condition i.e. 


$$
\frac{2 \pi B L}{\lambda_{d i p}}=2 k \pi
$$

then a resonance dip can be observed in the transmitted spectrum [64], which is given by

$$
\lambda_{\text {dip }}=B L k
$$

Where $k$ is an integer value. The wavelength spacing between the transmission dips can be expressed as,

$$
\Delta \lambda=\frac{\lambda^{2}}{B L}
$$

For VOC detection, the $B$ and $L$ values of the sensing film change upon exposure to VOCs. Thus the wavelength shift of polarization mode interference is modulated by the change in PMF length and/or refractive index. By demodulating the wavelength shift, the sensitivity towards target VOCs can be determined.

\subsection{Mach-Zehnder interferometer}

The Mach-Zehnder (MZ) Interferometer was developed independently by Ludwig Zehnder [65] and Ludwig Mach [66]. It is one of the most common interferometric techniques employed for sensing applications [67]. The MZ interferometer provides a flexible and robust platform for sensing applications that can be fiber-coupled and implemented on a microchip. There are three different variants of the MZ interferometer: Open path, fiber-based, and planar waveguide-based interferometers are shown in Figure 4. The MZ interferometer has been exploited for temperature [68][69], pressure [70], strain [71][72], seismology [73], vibration [74], current [75], magnetic field [76], water salinity [77] and bio-sensing applications [78].

In MZ interferometers, a coherent collimated light beam is split into two; one acts as a reference arm while the other acts as a sensing arm. The two light beams are then recombined to obtain an interference signal, as shown in figure 4 . The sensing arm is exposed to the measurand (temperature, pressure, gas molecules) which causes modulation of the interference signal. The phase difference for MZ interferometer is given by

$$
\phi=\frac{2 \pi}{\lambda}\left|n_{1} L_{1}-n_{2} L_{2}\right|+\phi_{o}
$$

Where $n_{1}$ and $n_{2}$ are effective refractive indexes of the two optical paths, $L_{1}$ and $L_{2}$ are transmission length of the two optical paths and $\phi_{o}$ is the initial phase. The phase difference is then demodulated to measure the concentration of gas molecules. 
(A)

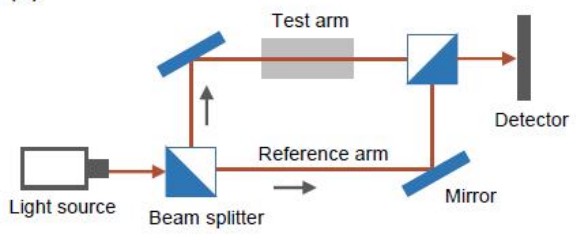

(B)

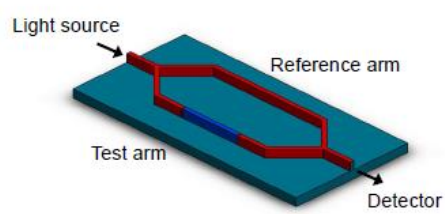

(C)

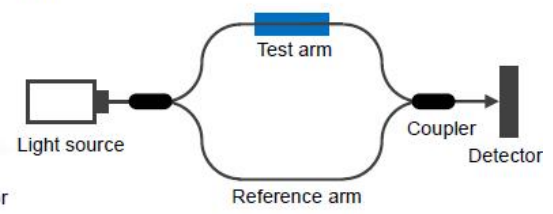

Figure 4: Schematic of Mach-Zehnder Interferometer (A) open space interferometer. (B) Chip-based MZ interferometer. (C) Fiber-based MZ interferometer.

\subsection{Pohl interferometer}

The Pohl interferometer is an amplitude splitting interferometer in which light beam from a point source is reflected from the surfaces with different optical properties (refractive index, reflectivity) forming an interference pattern [79]. The Pohl configuration offers a simple, quick and efficient approach for measuring the wavelength [38]. It has been applied for shop testing conditions, phase measurement and parallelism measurement of transparent surfaces [80][81][82]. For sensing applications, a simple Pohl configuration is constructed by depositing a sensing film on a substrate. For instance in Figure 5, the light reflected from the three interfaces form an interference pattern on the screen, which can be represented as [83],

$$
\begin{gathered}
I=I_{1}+I_{2}+2 \sqrt{I_{1} I_{3}} \cos \delta \\
\delta=2 y k \sin \left(\theta_{i}-\Delta \phi\right)
\end{gathered}
$$

where $k$ is the wavenumber, $y$ is the position of the fringe on the screen, $\theta_{i}$ is an angle between $I_{l}$ and $I_{3}$ and $\Delta \phi$ is the phase difference, given by.

$$
\Delta \phi=\frac{4 \pi d}{\lambda}\left(n_{2}^{2}-n_{1}^{2} \sin ^{2} \theta_{i}\right)^{\frac{1}{2}}+\frac{4 \pi d_{1}}{\lambda}\left(n_{3}^{2}-n_{1}^{2} \sin ^{2} \theta_{i}\right)^{\frac{1}{2}}
$$

Where $n_{2}$ and $n_{3}$ are the refractive indexes of glass substrate and PDMS film respectively. When VOCs interact with sensing film, $d_{l}$ and $n_{3}$ changes, which causes a change in $\Delta \phi$ inducing a shift in the fringes pattern.

(A)

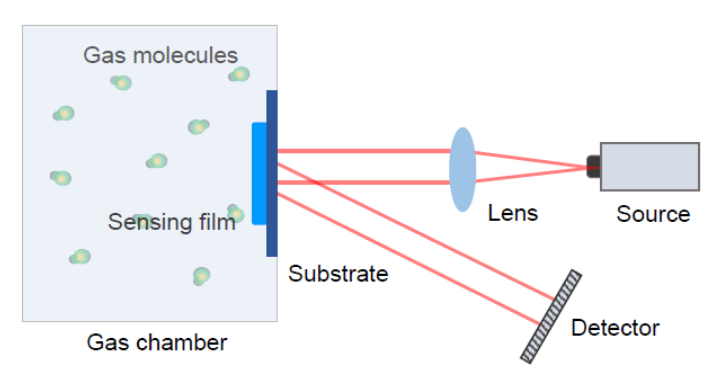

(B)

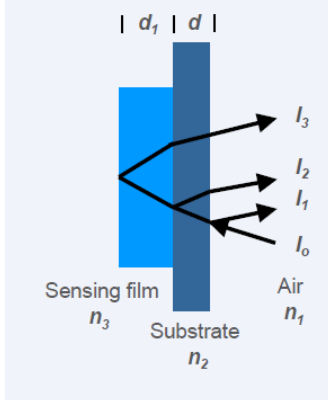

Figure 5. (A) Pohl optical arrangement for VOC detection. (B) The interference pattern is formed by light beams reflected from air-substrate interface, substrate-sensing film interface and air-sensing film interface. 


\section{Interferometry for VOC detection}

\subsection{Sensing films for Interferometry}

Optical properties and volume of a sensing film change when it is exposed to gas molecules. Interferometry quantifies these variations in terms of phase difference inferred from changes in the optical path length. The commonly used sensing films for VOCs are PDMS and zeolite. Other types of sensing films including polymethyl-methacrylate (PMMA), polychloro-para-xylylene (Parylene-C), SU-8, polyethylene glycol (PEG 400), PEG-1000, Norland optical adhesive (NOA 81) have also been reported for VOCs applications.

\subsubsection{PDMS sensitive thin film}

Poly(dimethylsiloxane) (PDMS), - $\left[\mathrm{O}-\mathrm{Si}\left(\mathrm{CH}_{3}\right)_{2}\right]$ is a silicone-based elastomer and is widely used in microfluidics and biomedical applications due to its features like optical transparency, chemical inertness, biocompatibility, low cost, flexibility, elasticity and tunable permeability [84] [85]. It is optically transparent in the wavelength range $230-800 \mathrm{~nm}$ [86][87]. PDMS has relatively stable physical properties in contrast to polymers with organic backbone, with a large free volume due to absence of crystallites which facilitate diffusion [88]. It undergoes volume and/or refractive index changes when it interacts with VOCs. Although the swelling of PDMS is not desired in many microfluidics applications, this property can be exploited for sensing applications when employed as a sensing film [89][90].

\subsubsection{Zeolite sensitive thin film}

Zeolites are microporous alumino-silicate crystal with uniform nanometric-scale pores systems. It discriminates molecules through size exclusion or shape selectivity. It can selectively adsorb molecules depending on the crystal structure, framework Si/Al ratio and type of framework cations [91], and has excellent chemical and optical properties. Zeolites have been extensively investigated for use in separation [92] and electrochemical sensors [93][94]. It is an excellent material for optical sensors due to a high surface-to-mass ratio, chemical selectivity and flexibility for surface chemistry modification. The optical properties of zeolites changes when molecular species are loaded on it depending on the type, amount and state of the molecules [95]. Zeolites exhibit different sensitivities towards different molecules depending on the molecule sieve. Thin films of zeolite integrated with different optical methods have been successfully applied for trace organic vapours detection [96][97].

\subsection{Application of Interferometry for VOC detection}

Different interferometric techniques have been applied for detection of various gases, for instance, hydrogen [47], $\mathrm{CO}_{2}$ [98], ammonia [99], $\mathrm{N}_{2} \mathrm{O}$ [100], HS [101] and a number of VOCs. Recently, there is a growly interest in the use of interferometry for VOC detection. We review here different interferometric approaches deployed for VOC detection, as summarized in Table 3. Fibre-based interferometry is discussed first followed by chip-based interferometers and then other types of interferometers. 
An FP gas sensor was developed by Liu et al. [102] using a metal-coated FP cavity for detection of VOCs such as hexanol, methanol and acetone. The interferometer was fabricated by depositing silver and a gas-sensing film sequentially at the end of an optical fiber, and FP cavity was realized by silverpolymer and polymer-air interfaces as shown in figure 6. Polyethylene glycol (PEG-400) and Norland optical adhesive (NOA-81) were applied as a sensing film due its optical and chemical properties. The sensitivity of 3.5 picometers $(\mathrm{pm}) / \mathrm{ppm}$ with a detection limit of $1 \mathrm{ppm}$ was reported using PEG-400 as a sensing film. The design was extended to integrate with $\mu \mathrm{GC}$ for on-column detection of toluene, decane, methanol and Dimethyl-methyl-phosphonate (DMMP) [103]. The sensitivity was enhanced to sub-nano gram level, and limit of detection down to $50 \mathrm{pg}$ (105.6ppb for $\mu \mathrm{GC}$ with length and diameter of $1.9 \mathrm{~m}$ and $0.25 \mathrm{~mm}$ respectively) was achieved for DMMP. A sensitivity of $4.75 \mathrm{mV} / \mathrm{ng}$ and $77 \mathrm{mV} / \mathrm{ng}$ was reported for decane and DMMP respectively.

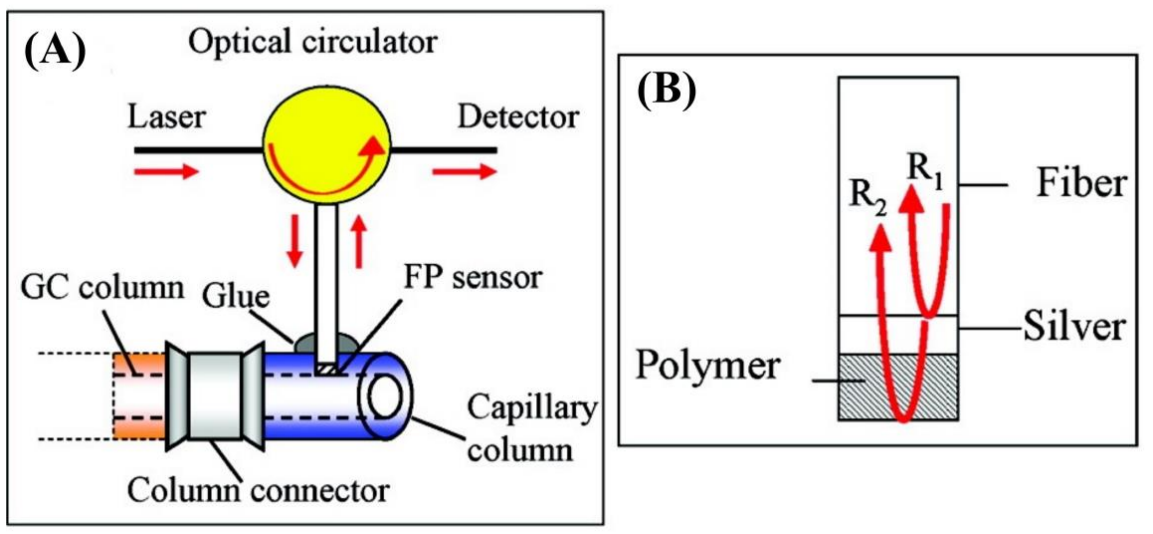

Figure 6. (A) Schematic of the FP sensor integrated with $\mu \mathrm{GC}$ column, light source and detector. (B) Schematic of the FP sensor formed by coating sequentially the end of the fiber with silver and polymer. Adapted from [103].with permission American Chemical Society.

Ning et $a l$. [104] demonstrated a sensitive FP and Sagnac Interferometer functionalized with PDMS for simultaneous multiple VOC detection. Ethanol and 2-propanol were detected and differentiated using a second-order inverse matrix method. An in-line FP sensor was fabricated by using a single-mode hollow optical fiber (diameter $=125 \mu \mathrm{m}$ and length $=50 \mu \mathrm{m}$ ) with a PDMS (thickness $=15 \mu \mathrm{m}$ ) coating on the tip of fiber. The FP cavity was formed by the fiber end face and the interface between air and PDMS. A sensitivity of $1.17 \times 10^{-3} \mathrm{~nm} / \mathrm{ppm}^{\mathrm{e}}$ and $1.61 \times 10^{-3} \mathrm{~nm} / \mathrm{ppm}$ was reported for ethanol and 2-propanol respectively. A Sagnac interferometer was fabricated by splicing a polarization-maintaining fiber (PMF) with a length of $10 \mathrm{~cm}$ between the SM fibers and coated with PDMS similar to Figure 3. The Sagnac interferometer showed a non-linear response for different concentration of VOCs. A sensitivity of $9.02 \times 10^{-4} \mathrm{~nm} / \mathrm{ppm}$ and $2.71 \times 10^{-3} \mathrm{~nm} / \mathrm{ppm}$ was measured for ethanol and 2-propanol respectively. The diffusion of 2-propanol from the PDMS was a drawback of Sagnac interferometer for repeated use. The

\footnotetext{
${ }^{\mathrm{e}} \mathrm{nm} / \mathrm{ppm}$ (nanometer/part-per-million)
} 
FP sensor demonstrated fast and reproducible response compared to Sagnac interferometer and was attributed to the miniature size of FP cavity and thin coating of PDMS.

A similar approach was adopted by the same group to demonstrate an FP interferometer by replacing the PDMS coating with zeolite for detection of 2-propanol [105]. An arc-shaped inline FP cavity was formed by zeolite film and the spherical end of the fiber as shown in figure 7 . The wavelength shift is a function of the refractive index of zeolite film. A sensitivity of $0.92 \mathrm{~nm} / \mathrm{ppm}$ towards 2-propanol for concentration 0-70 ppm was recorded. The sensor demonstrated good thermal stability, repeatability and fast response with response time less than $2 \mathrm{sec}$.

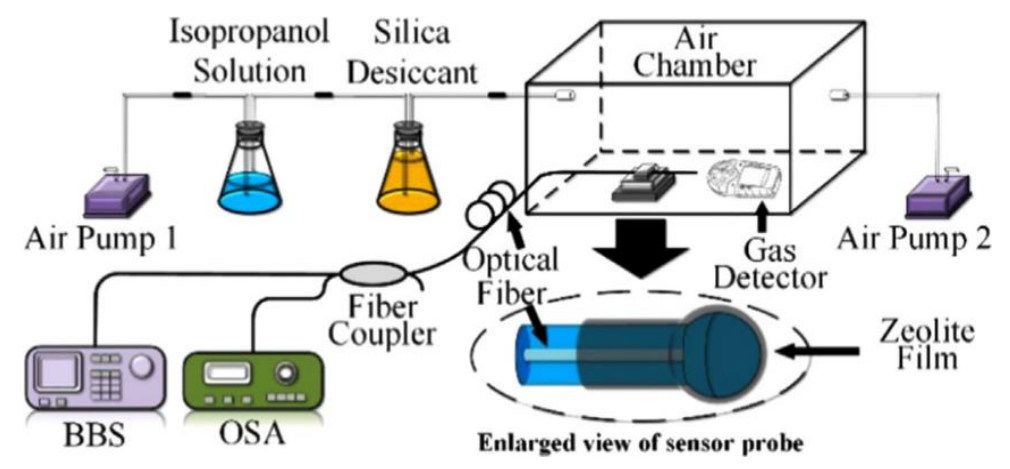

Figure 7. Schematic of the experimental setup with zeolite coated FP interferometer. BBS and OSA represent BroadBand Light Source and Optical Spectrum Analyser, respectively. Reprinted from the [105] with permission from Elsevier.

Wu et al. [106] applied a zeolite coated FP interferometer for 2-propanol and formaldehyde detection. The fiber spherical shape (diameter, 192 $\mu \mathrm{m}$ ) and zeolite coating (thickness, $25 \mu \mathrm{m}$ ) constituted the FP cavity as shown in figure $8(\mathrm{~A})$. The sensitivity of $281.9 \mathrm{pm} / \mathrm{ppm}^{\mathrm{f}}$ and $4.99 \mathrm{pm} / \mathrm{ppm}$ was found for 2propanol and formaldehyde respectively. The sensor was 56 times more sensitive towards 2-propanol than formaldehyde owing to their molecular sizes in comparison with the zeolite size. The sensor was tested for a mixture of 2-propanol with different concentrations of formaldehyde (0-150 ppm) as shown in figure 8 (B) and good stability and repeatability was reported.

\footnotetext{
${ }^{\mathrm{f}} \mathrm{pm} / \mathrm{ppm}$ (pico-meter/part-per-million)
} 
(A)

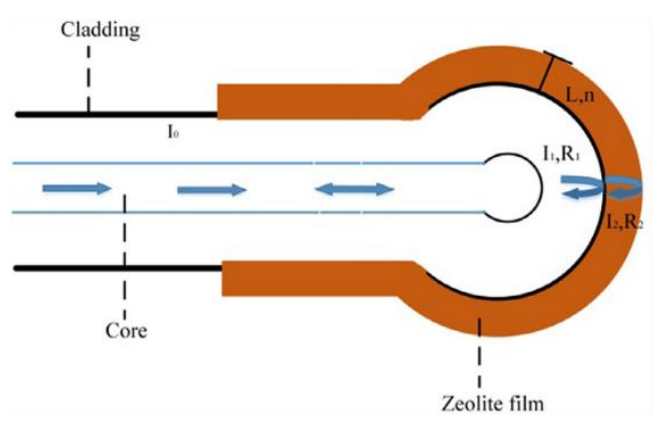

(B)

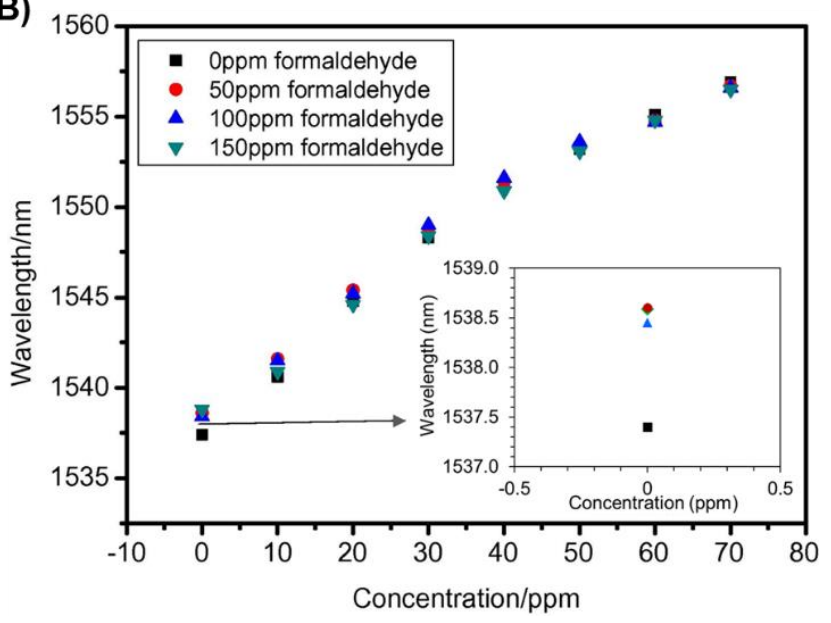

Figure 8. (A) Structure of Zeolite-coated FP cavity. (B) The effect of different formaldehyde concentrations for isopropanol measurement. Reprinted from [106] with permission from Elsevier.

An extrinsic FP interferometer made by a micro air-cavity in PDMS at the fiber-end was demonstrated by Kacik et al. [108] for toluene detection. The surface interface between the fiber/air and air/PDMS served as mirrors and the reflected beams formed an interference pattern. The micro air-cavity (diameter, $70 \mu \mathrm{m}$ ) was fabricated by treating the fiber end with paraffin wax and then coated with PDMS as shown in figure 9. The sensor showed sensitivity of $0.15 \mathrm{~nm} / \mathrm{g}-\mathrm{m}^{-3}$ to $1.4 \mathrm{~nm} / \mathrm{g}-\mathrm{m}^{-3}$ for concentration of 0.833 $\mathrm{g}-\mathrm{m}^{-3}$ to saturation in $5 \mathrm{sec}$ response time. The sensor was compact, simple-to-fabricate and had a fast response. The same group developed a PDMS microfiber Mach-Zehnder interferometer coupled between an SM fiber for nano-range detection [107]. A PDMS microfiber and air were used as a test arm and a reference arm respectively. The spherical shaped head of the SM fiber was used as a beam splitter/coupler as in figure 10 . The interferometer demonstrated a nanometric level variation up to 250 $\mathrm{nm}$ when exposed to VOCs.

\section{(A)}

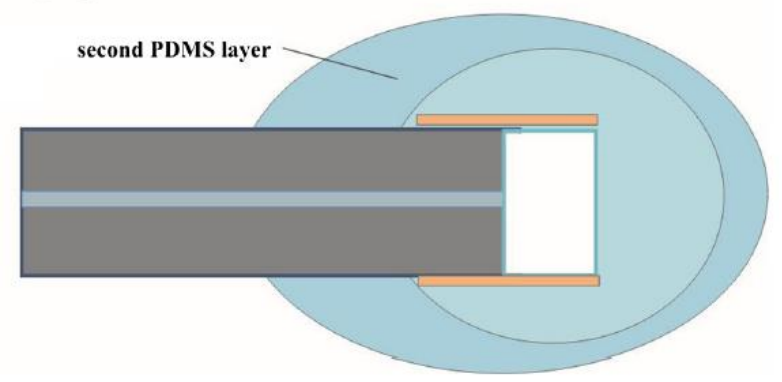

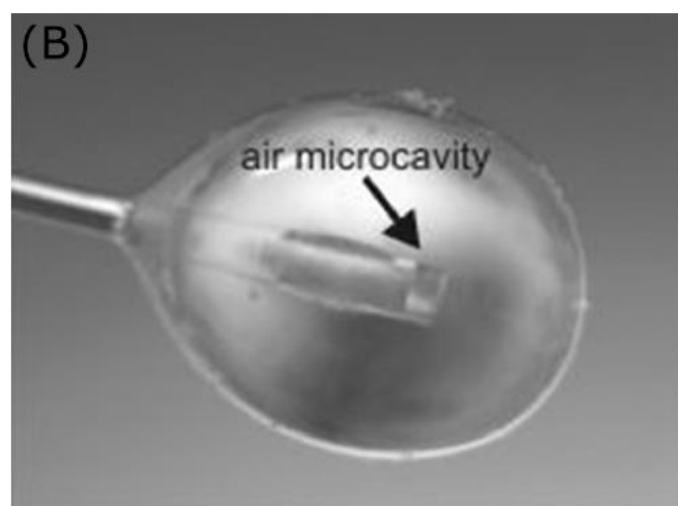

Figure 9. (a) Schematic of the FP cavity. Air cavity inside PDMS constitutes the FP cavity. (b) Micrograph of the fabricated PDMS FP sensor. Reprinted from [108] with permission from Elsevier. 
(A)

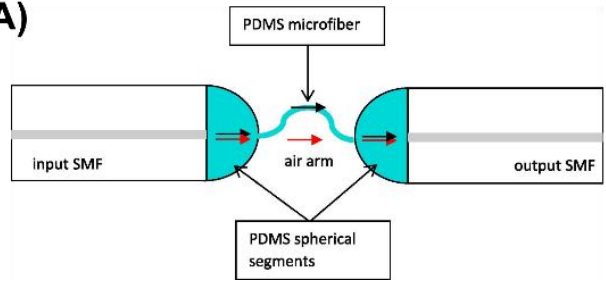

(B)

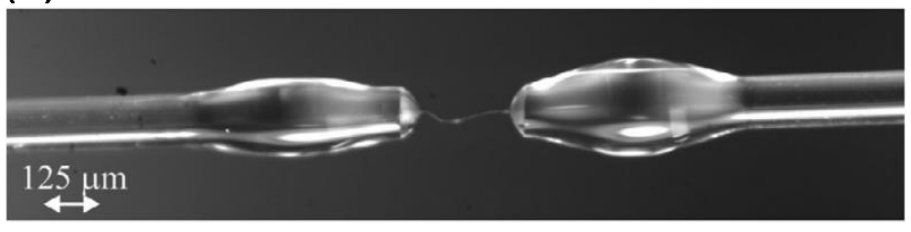

Figure 10. (a) Schematic of MZ interferometer. PDMS microfiber works as a sensing beam. (b) Micrograph of fabricated MZ interferometer. Reprinted from [107] with permission from Elsevier.

A PMMA (Polymethyl methacrylate) functionalized FP interferometer was developed by Yu et al. [109] for ethanol and acetone detection with good selectivity. The FP cavity was created by coating PMMA on the end of a glass tube and then inserting the SM fiber into the tube, as shown in figure 11. A sensitivity of $2.7 \mathrm{pm} / \mathrm{ppm}$ and $2.17 \mathrm{pm} / \mathrm{ppm}$ was measured for ethanol and acetone respectively. The sensor distinguished different VOCs with good repeatability and showed low sensitivity towards inorganic molecules such as $\mathrm{NH}_{3}, \mathrm{CO}$ and $\mathrm{H}_{2}$.

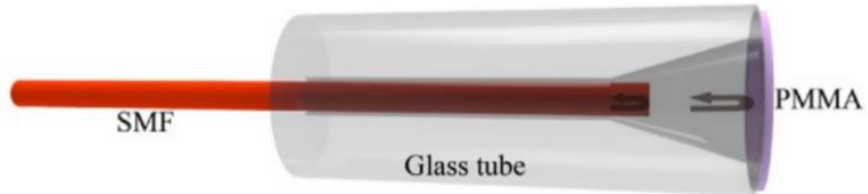

Figure 11. Schematic of FP interferometer. The FP cavity is formed by the end of fiber and PMMA film. Reprinted from [109] with permission from the Optical Society(OSA) publishing.

A Sagnac interferometer functionalized with PDMS was designed by Wu et al. [110] for detection of 2propanol with a limit of detection of 19.3ppm. A PMF (length $=8 \mathrm{~cm}$ ) functionalized with PDMS was inserted between the two ends of SM fiber and was exposed to VOCs. The mixing ratio of the PDMS precursor and curing agent was investigated, and sensitivity of $0.001 \mathrm{~nm} / \mathrm{ppm}$ and $0.002 \mathrm{~nm} / \mathrm{ppm}$ was found for mixing ratios of 10:1 and 5:1 respectively. A sensitivity of $1.03 \mathrm{pm} / \mathrm{ppm}$ was observed for concentrations in the $0-6000 \mathrm{ppm}$ range with a response time of $1 \mathrm{~min}$.

A chip-size VOCs sensor was developed by Reddy et al. [111] using FP array inside a $\mu$ GC microfluidic channel. The FP array was integrated with the $\mu \mathrm{GC}$ column and tested for four VOCs mixture: acetone, methanol, heptane and toluene as shown in figure 12. Each FP sensor $(200 \mu \mathrm{m} \times 200 \mu \mathrm{m}$ with a depth of $1.3 \mu \mathrm{m}$ ) was fabricated inside a microfluidic channel by coating a thin polymer layer into pre-etched wells in a silicon substrate as shown in figure 13. Four polymers (i.e. OV-1(PDMS), OV-73 (diphenyldimethylsilicone), OV-215(trifluoropropylmethylsilicone) and OV-1701 (dimethylphenyl cyano substituted)) were coated as a sensing film, and each polymer exhibited a different response to different analytes. The VOCs mixture was separated by $\mu \mathrm{GC}$ and then injected into the sensor module. The airpolymer and polymer-substrate interface formed an FP cavity whose resonance length changed when exposed to VOCs. The sensor had good sensitivity, and detection limits of $0.79 \mathrm{pg}$ (28 ppb) and 0.64pg 
(25 ppb) were obtained for toluene and heptane respectively. Pattern analysis was used to analyse the data from the multiple FP sensors to discriminate the different VOCs. The sensitivity was improved compared to two FP sensors array with PDMS and SU-8 layer developed by the same group [112]. In that study, a sensitivity of $2900 \mu \mathrm{V} / \mathrm{ng}^{\mathrm{g}}$ (limit of detection of $1.7 \mathrm{ppm}$ ) was achieved for toluene using a PDMS layer.

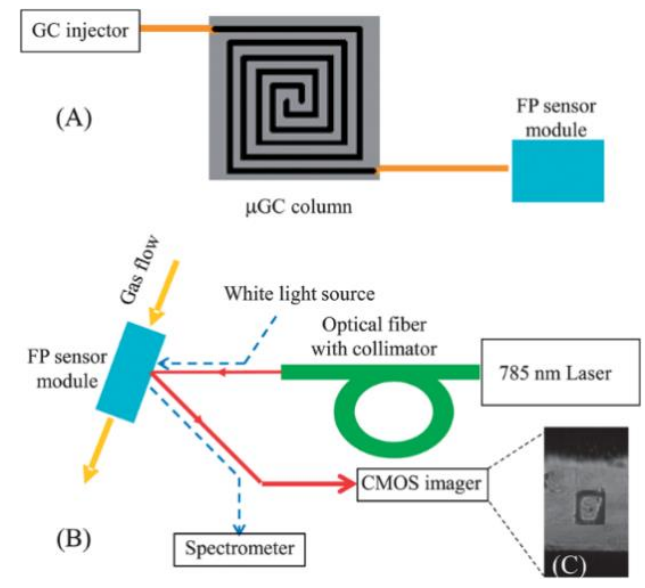

Figure 12. (A) Schematics of FP sensors array integrated with $\mu$ GC. (B) Schematic of the optical detection setup. The laser is integrated with the FP sensor using optical fiber. The CMOS imager provides quantitative information about the polymer response to the vapour analytes. Reprinted from [111] with permission from Royal Society of Chemistry.

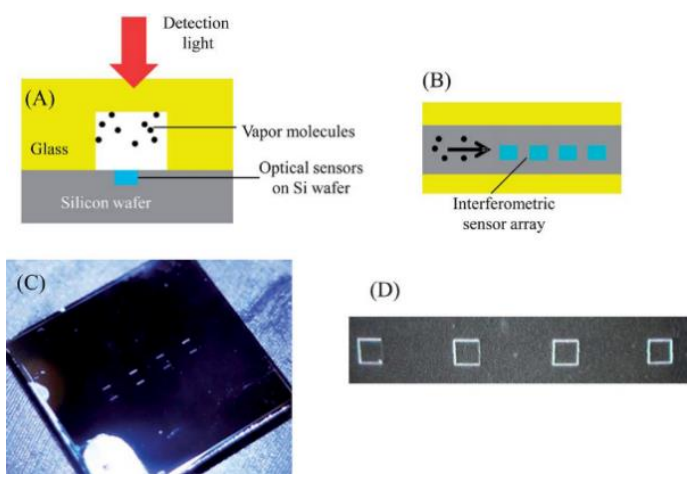

Figure 13. (A) Cross-section view of FP sensors array (B) Top-view of array (C) Image of the sensors array with overall size of $8 \mathrm{~mm} \times 6 \mathrm{~mm}$ (D) Image of 4 wells with separation distance of $800 \mathrm{um}$. Reprinted from [111] with permission from Royal Society of Chemistry.

A novel on-chip VOCs sensor was demonstrated by St-Gelais et al. [113] using deformable silicon FP interferometer. The FP interferometers were functionalized with PDMS and PDMSpolydiphenylsiloxane copolymer (PDMS-PDPS) and were tested to detect m-xylene and cyclohexane. A deformable FP sensor was constructed using silicon air Bragg reflectors with a sensing polymer between the two mirrors as shown in figure 14. The monolithic integration of the microfluidics system and optical fiber alignment grooves was realized by the vertical mirrors and in-plane optical axis. A detailed analytical model with numerical analysis was developed, and it was found that mechanical

g $\mu$ V/ng(micro-volt/nano-gram) 
deformation was the dominant sensing mechanism. The sensor demonstrated high sensitivity of 0.023 $\mathrm{nm} / \mathrm{ppm}$ for m-xylene. A limit of detection of 34ppm was achieved which was limited by the flowmeters used in the study. According to the author, a limit of detection of $1.6 \mathrm{ppm}$ and $6.3 \mathrm{ppm}$ can be obtained for $\mathrm{m}$-xylene and cyclohexane respectively. The on-chip interferometer can potentially be extended to multiple parallel interferometers without the need of laborious alignment process.

(A)

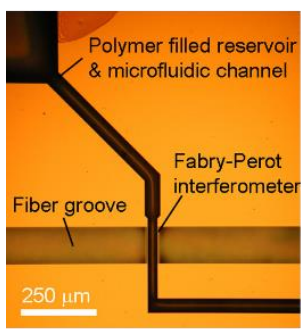

(B)

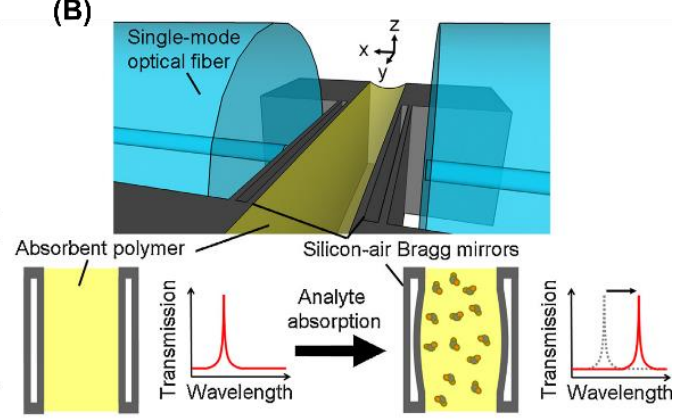

Figure 14. (A) Optical micrograph of a polymer-coated device showing monolithically integrated microfluidics system and the optical fiber alignment groove with FP interferometer. (c) Schematics of FP interferometer with working principle. A shift in the resonance wavelength is observed upon absorption of the sample into the polymer. Adopted from [113] with permission from Elsevier.

A miniaturized complementary metal-oxide semiconductor (CMOS)-MEMS based FP interferometer with photocurrent readout was designed by Maruyama et al. [114] for detection of ethanol. Polychloro-para-xylene (Parylene-C) was used as a sensing film which bulged upon exposure to ethanol. An FP cavity was formed by the thin flexible Parylene-C film (350nm), air gap (300nm) and the silicon oxide film $(400 \mathrm{~nm})$ on the top of the silicon substrate as shown in figure 15. A novel signal transduction was employed by using the FP interferometer to convert the mechanical deformation of sensing film to a change in light transmittance detected by a photodiode. The sensor size was $5 \mathrm{~mm}^{2}$ with a LED source. A signal processing circuit was integrated to quantify the exposed gas molecules. The sensor demonstrated a good sensitivity of 50nm deformation of the film for $80 \mathrm{ppm}$ of ethanol.

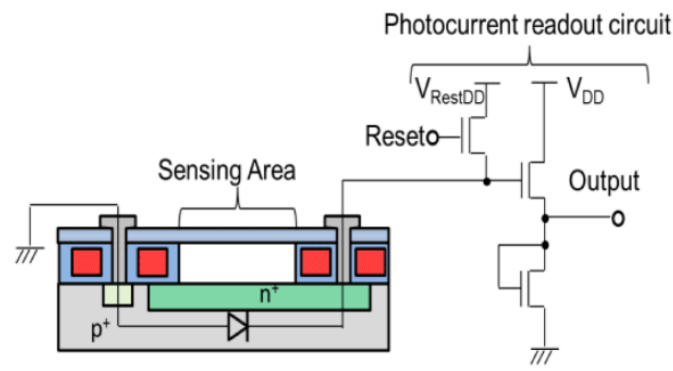

(a)

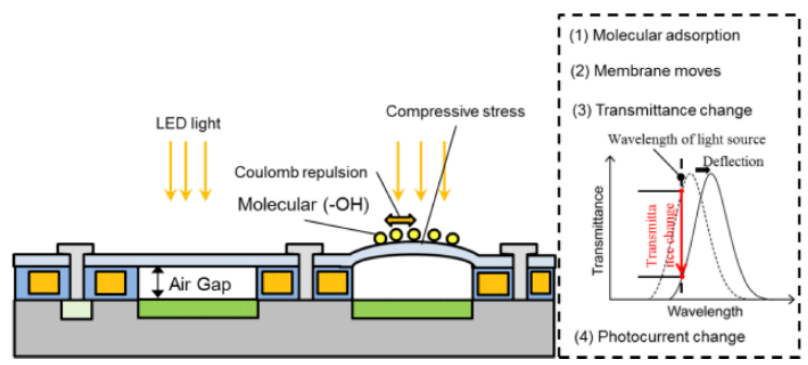

(b)

Figure 15. (a) Schematics of the MEMS FP interferometer sensor. (b) The working mechanism of the sensor. The deformation model of sensing film due to Coulomb repulsion. Reprinted from [114].

Martinez et al. [83] developed an open path interferometer using Pohl configuration for detection of alcohol, ether and alkanes. A PDMS film (thickness, $8 \mu \mathrm{m}$ ) was deposited on the backside of glass while 
front side was exposed to a light beam. The reflected light from three interfaces, i.e. air-glass, glassPDMS and PDMS-air formed an interference pattern. The sensor showed a sensitivity of $0.14 \mathrm{nW} / \mathrm{ppm}^{\mathrm{h}}$ and $0.12 \mathrm{nW} / \mathrm{ppm}$ for propyl acetate and octane respectively for concentration range 0-24000 ppm with good reproducibility. The sensor demonstrated good selectivity towards esters compared to alcohols. The response of the sensor was dominated by the volume change in comparison to refractive index change. It was found that a higher molecular volume caused a higher volume change of PDMS due to molecular diffusion.

Spectral interferometry was used to detect alkanes and halogenated hydrocarbons by employing a thin film of polysiloxane with good linearity [115]. The detection limits down to $100 \mathrm{ppm}$ with time response less than $1 \mathrm{sec}$ was demonstrated. A good linearity of 40-2600 ppm and up to $10^{4} \mathrm{ppm}$ was obtained using DMPS layer for tetrachloroethene and perfluroethylene respectively.

A Michelson interferometer was tested by Marzuarman et al. [116] for detection of benzene and ethanol without employing sensing film. The number of fringes shift (pixels) was used to calculate the concentration of gas molecules. A sensitivity of 0.006 pixels $/ \mathrm{ppm}$ and 0.015 pixels $/ \mathrm{ppm}$ with good linearity of 1611-32210 ppm and 964-19290 ppm was found for ethanol and benzene respectively.

\section{Comparison and challenges in the interferometric sensors}

Different interferometry techniques have been applied as discussed for trace level detection of VOCs with good sensitivity, i.e. limit of detection from $28 \mathrm{ppb}$ to $20 \mathrm{ppm}$ have been obtained. Most of the techniques are based on FP interferometry. Optical-fiber and chip-based interferometers were designed to achieve miniaturization, robustness, multiplexing, ease of fabrication and integration. A comprehensive comparison of different interferometric techniques is summarized in Table 3. Different performance parameters, i.e. sensitivity, linearity and time response of each technique with sensing film employed are presented. Most of the techniques used are fiber-base interferometry due to its ease of operation, fabrication and integration with the different component of the interferometer. A detection limit down to $28 \mathrm{ppb}$ was demonstrated for toluene using FP interferometer coupled with $\mu$ GC column [117].

Interferometric based VOC detection techniques are simpler and have a flexible structure, good mechanical properties, easy fabrication process without the need of different optical fiber processes (i.e. polishing, chemical etching, and tapering process). However, demodulation of interference spectrum and periodic output signal are the drawbacks with the use of interferometry for gas sensing applications. For instance, the existence of multi-mode in MZ interferometer will make the extraction of peaks from the spectrum prone to errors. In Sagnac interferometer, the fiber is prone to external factors like

\footnotetext{
${ }^{\mathrm{h}} \mathrm{nW} / \mathrm{ppm}$ (nano-watt/parts-per-million)
} 
temperature, humidity and vibration which can introduce errors in the measurement. In FP interferometer, the disadvantages are the large transmission losses, cavity size limitation due to coupling losses and offset of the fiber end-faces.

\subsection{Existing challenges of the sensors}

\subsubsection{Sensing film}

The sensitivity of an interferometer depends on the interaction between the analyte and the sensing film, which in turns depend on several factors including the polarity of the gas and sensing film, the volatility of the analyte, the presence of functional groups, the gas molecular weight and size. Uniformity, surface roughness, thickness, thermal stability and development process of the sensing film also affect the response of film-mediated sensors [118]. For instance, the mixing ratio of PDMS elastomer and hardener affects the absorption of gases into the PDMS. Ning et al. [104] investigated the effect of mixing ratio of elastomer and hardener for PDMS and found that better sensitivity is achieved at a ratio of 5:1 as shown in figure 16. The curing temperature can also change the optical properties of PDMS [119]. The thermal and chemical stabilities of sensing film can affect the lifetime of the sensor.

The partition coefficient $\left(\mathrm{K}_{\mathrm{pa}}\right)$ of each polymer-analyte combination is taken into account for selecting a sensing film. A higher $\mathrm{K}_{\mathrm{pa}}$ value yields a higher sensitivity, but it also increases the retention time (lower diffusion constants) [120]. St-Gelais et al. [113] demonstrated that PDMS has a faster time response towards cyclohexane than for m-xylene. However, the sensitivity is decreased four-fold for cyclohexane than m-xylene. The disparity is due to the difference in the partition coefficient values of the film and analyte. Sensitivity is improved by using sensing film with a uniform surface and high surface area for absorption/desorption. For instance, the sensitivity of an FP interferometer was improved by using an arc-shaped head which increased the interfacial area between the zeolite and fiber head. One of the solutions to enhance the gas detection specificity is to use a polymer matrix with different properties, as different polymers respond differently according to the polarity, partition coefficient and refractive index. These polymer matrices can be tailored according to the desired class of analytes.

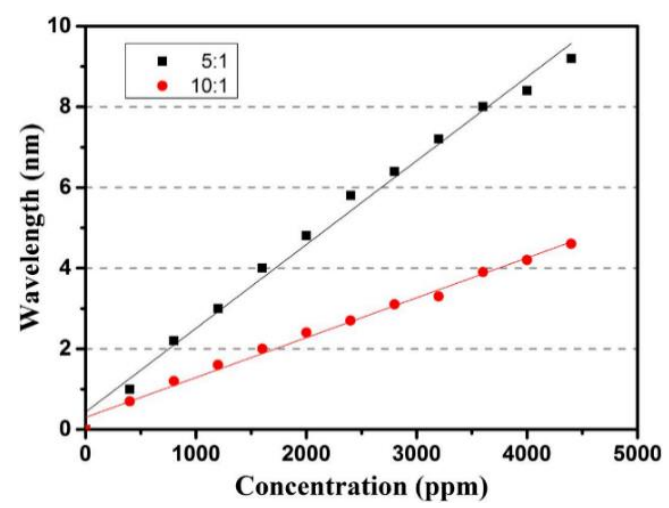


Figure 16. Comparison of wavelength change for the PDMS with different development process, i.e. mixing ratio of elastomer and hardener. Reprinted from [104] with permission from Optical Society (OSA) publishing.

\subsubsection{Slow time response}

The time response and recovery time is a drawback for continuous real-time gas monitoring in interferometric film-mediated sensors. For PDMS, the recovery time is slow which can affect the repeatability and continuous use of the sensor. The time response and repeatability can be improved by using thinner PDMS film or by optimizing the development process of PDMS film. The sensor response is mainly determined by the gas diffusion into the polymer. A thinner sensing film will absorb/desorb the analyte quickly as the diffusion time inside the solid sensing film is proportional to the square of length. For example, the Sagnac interferometer developed by Ning et al. had a slow time response compare to the FP interferometer due to the high volume of PDMS on it [104].

\subsubsection{Temperature and humidity influences}

The physiochemical properties of sensing film are sensitive to temperature, and a variation can induce uncertainties in the measurement. The diffusion and partition coefficient of PDMS depends upon temperature [121]. Humidity has a negative effect on both the sensitivity and response rate of the sensing film. The adsorbed $\mathrm{H}_{2} \mathrm{O}$ into PDMS or zeolite reduces the diffusion rate of VOCs into the sensing film. For a durable sensor, suitable and robust packaging is needed.

\subsubsection{Nonlinear output}

Non-Linear response of a sensor is not a desired characteristic since the calibration becomes complicated while the quantification becomes risky. In addition, linearity is often subjected to environmental factors like temperature, pressure, humidity and external vibration. For example a non-linear behaviour was observed with FP interferometer for different toluene concentration as shown in figure 17 [108]. The reason was attributed to the non-linear relationship between the toluene absorption and physiochemical properties of the sensing film. The film thickness can also cause changes in the response time.

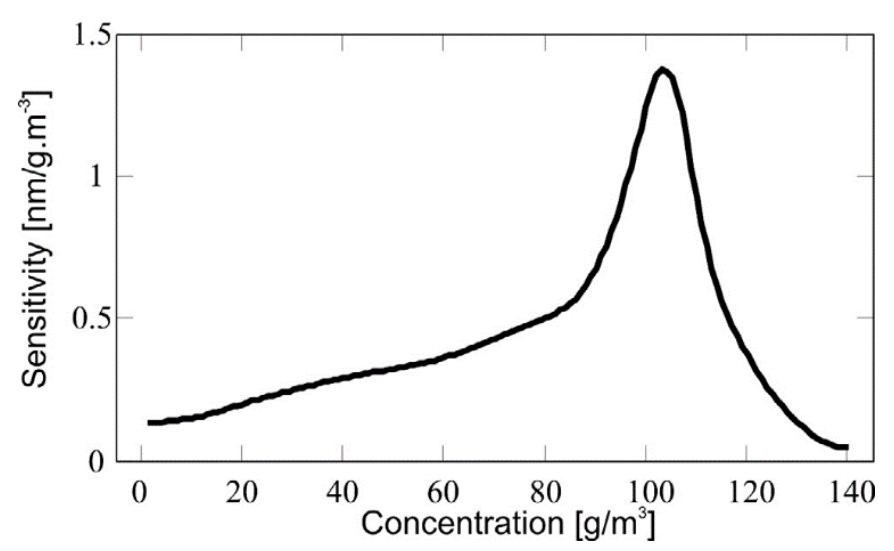

Figure 17. Variation of sensitivity with the gas concentration of toluene. Reprinted from [108] with permission from Elsevier. 


\subsubsection{Data acquisition and analysis}

The data analysis of an interferometry based sensor can be resource-intensive. For most of the interferometric techniques, a high-resolution Optical Spectrum Analyzers (OSA) were employed, which is not a cost-effective approach to meet the challenge of miniaturization and portability. Using a high sensitive OSA at a portable scale is a large challenge for future requirements.

Direct phase retrieval techniques, i.e. phase stepping interferometry and heterodyne interferometry is a good candidate for phase measurement [122]. A resolution up to $\lambda / 1000$ can be achieved with heterodyne interferometry [123]. In phase stepping technique a known phase steps are introduced into one of the beams, and the phase is retrieved by different phase-retrieval methods, for example, three-step method, four-step method, five-step method and Carre method [124]. Phase stepping technique is suitable for liquid flow measurement and is not recommended for gas analysis. In heterodyne interferometry, a frequency shift is introduced into two beams using acoustics optics modulators. A modulated signal with a frequency difference between the two beams is acquired either by CMOS or CCD detector. Recently such a heterodyne interferometry approach has been explored for VOC detection [125].

\section{Future Prospects and Conclusion}

The ideal features for sensors are simplification, miniaturization and multiplexing with high sensitivity and selectivity, wide operating range and good precision. In film-mediated sensors, selectivity is considered as one of the main challenges for real-life applications where the sensing film can absorb/adsorb a number of molecules. The recent progress in artificial intelligence, machine learning and data analysis offers a solution to tackle the selectivity of sensors [126]. For instance, the different VOCs can be differentiated by using inverse matrix methods [104] or by employing artificial neural networks [127]. The addition of a separation column and pre-concentration with the gas sensor can also enhance the sensitivity and selectivity of sensor. The higher sensitivity achieved by Reddy at $a l$. and Liu et $a l$. are attributed to the integration of interferometer with $\mu$ GC columns [112] [103][117]. In order to achieve high accuracy and precision of measurement, the effects of external factors such as temperature, pressure, humidity, gas dynamics around the sensor have to be well-understood. Most of the interferometric techniques are single-point which means that the sensor is targeting the molecules in a limited domain. For real-life application, a multipoint detection of gas molecules covering the whole gas domain and a maximum interaction of gas molecules with a sensor surface is desired. The different technique can be employed for enhancing the interaction of gas molecules with sensor. Kacik et al. increase the interaction of gas molecules with the sensing film by slowly rotating the gas chamber having the FP sensor [108]. Some of the new methods such as slow light [128], whispering gallery mode [129] and Vernier effect [130] can provide a solution to increase the interaction of gas molecules with light beam. The exposure limits for carcinogenic VOCs like benzene and formaldehyde are in the sub-ppb range as shown in table 1 . It can be challenging to detect such a low concentration with only 
interferometry. However, detection of such an ultra-low concentration can be realized by employing interferometry with a pre-processing of the gas mixture for instance separation or pre-concentration.

The recent advancement in material science has given an opportunity to deploy new materials as a sensing film. Recently state-of-art materials such as metal-organic framework (MOF) have shown tremendous potential for gas sensing applications. It can be tailored according to desired applications and can be exploited for gas sensing using interferometric sensors [131][132][133].

In this study, different interferometry technique for the detection of VOCs are discussed. The sensor design, working principle and different analytical performance parameters including sensitivity, linearity, and response time were presented in details. Different sensing films and materials employed for the target VOCs, pros and cons of each technique were outlined. New approaches for improving the performance of sensor concerning the material selection, data acquisition and analysis are suggested. Interferometry has good potential to achieve a highly precise and sensitive gas sensor for domestic and industrial applications. Today the emerging growth in the area of electronics, optics, materials science and data analysis have open new avenues for research and can be extended to interferometry to realize an interferometric sensor with high precision and sensitivity.

\section{Acknowledgments}

This work is supported by European Union's Horizon 2020 research and innovation programme under the Marie Skłodowska-Curie Innovative Training Network-MIGRATE (Miniaturized Gas flow foR Applications with Enhanced Thermal Effects), grant agreement No. 643095 [H2020-MSCA-ITN-2014]. 
Table 3. Comparison of different interferometry techniques for VOCs detection.

\begin{tabular}{|c|c|c|c|c|c|c|c|c|c|}
\hline $\begin{array}{l}\text { S } \\
\text { No }\end{array}$ & Interferometer & Type & Molecules detected & Sensing film & $\begin{array}{l}\text { Linear response } \\
\text { range }\end{array}$ & Sensitivity & Time response & Remarks & Ref \\
\hline 1 & $\begin{array}{l}\text { FP } \\
\text { Interferometer }\end{array}$ & $\begin{array}{l}\text { Fiber- } \\
\text { based }\end{array}$ & $\begin{array}{l}\text { Hexanol, methanol } \\
\text { and acetone }\end{array}$ & $\begin{array}{l}\text { Polyethylene glycol(PEG } \\
400) \text { and Norland optical } \\
\text { adhesive (NOA 81) }\end{array}$ & $0-4000 \mathrm{ppm}$ & $\begin{array}{l}3.53 \mathrm{pm} / \mathrm{ppm} \text { for methanol with PEG sensing } \\
\text { film. Limit of detection(LOD): } 1 \mathrm{ppm} \text { and } \\
0.1 \mathrm{pm} / \mathrm{ppm} \text { with NOA sensing film (LOD: } \\
10 \mathrm{ppm} \text { ) }\end{array}$ & 10 seconds for pulse mode & $\begin{array}{l}\text { The sensor was tested in } \\
\text { continuous and pulse mode }\end{array}$ & [102] \\
\hline 2 & $\begin{array}{l}\text { FP } \\
\text { Interferometer }\end{array}$ & $\begin{array}{l}\text { Fiber- } \\
\text { based }\end{array}$ & $\begin{array}{l}\text { Toluene, decane, } \\
\text { methanol and } \\
\text { Dimethyl- } \\
\text { methylphosphonate } \\
\text { (DMMP) } \\
\end{array}$ & PEG 1000 and PDMS & $\begin{array}{l}0-20 \mathrm{ng} \text { for DMMP. } \\
0-50 \mathrm{ng} \text { for decane } \\
\text { using PEG } 1000\end{array}$ & $\begin{array}{l}4.75 \mathrm{mV} / \mathrm{ng} \text { for decane and } \\
77 \mathrm{mV} / \mathrm{ng} \text { for DMMP (LOD :50 } \mathrm{pg}(105.6 \\
\mathrm{ppb}))\end{array}$ & - & $\begin{array}{l}\text { FP sensor can be easy to } \\
\text { integrate with the GC } \\
\text { column and can be tailored } \\
\text { as per analytes. }\end{array}$ & [103] \\
\hline 3 & $\begin{array}{l}\text { FP and Sagnac } \\
\text { interferometer }\end{array}$ & $\begin{array}{l}\text { Fiber- } \\
\text { based }\end{array}$ & $\begin{array}{l}\text { Ethanol and 2- } \\
\text { propanol }\end{array}$ & PDMS & $0-6800 \mathrm{ppm}$ & $\begin{array}{l}9.02 \times 10^{-4} \text { to } 5.14 \times 10^{-4} \mathrm{~nm} / \mathrm{ppm} \text { for ethanol. } \\
\text { and } 2.71 \times 10^{-3} \text { to } 7.78 \times 10^{-4} \mathrm{~nm} / \mathrm{ppm} \text { for } 2- \\
\text { propanol }\end{array}$ & $\begin{array}{l}15 \mathrm{sec} \text { for FP interferometer, } \\
40 \mathrm{~min} \text { for Sagnac } \\
\text { interferometer }\end{array}$ & $\begin{array}{l}\text { Multiple VOC were } \\
\text { simultaneously measure by } \\
\text { using a second-order } \\
\text { matrix inverse algorithm. }\end{array}$ & [104] \\
\hline 4 & $\begin{array}{l}\text { FP } \\
\text { interferometer }\end{array}$ & $\begin{array}{l}\text { Fiber } \\
\text { based }\end{array}$ & Isopropanol & Zeolite & 0ppm-70ppm & $0.92 \mathrm{~nm} / \mathrm{ppm}$ & $2 \mathrm{sec}$ & - & [105] \\
\hline 5 & $\begin{array}{l}\text { FP } \\
\text { interferometer }\end{array}$ & $\begin{array}{l}\text { Fiber } \\
\text { based }\end{array}$ & $\begin{array}{l}\text { Isopropanol and } \\
\text { formaldehyde }\end{array}$ & Zeolite & $\begin{array}{l}0-1000 \mathrm{ppm} \text { for } \\
\text { formaldehyde }\end{array}$ & $\begin{array}{l}281.9 \mathrm{pm} / \mathrm{ppm} \text { for isopropanol and } 4.99 \\
\mathrm{pm} / \mathrm{ppm} \text { for formaldehyde }\end{array}$ & $2 \mathrm{sec}$ & - & [106] \\
\hline 6 & $\begin{array}{l}\text { FP } \\
\text { interferometer }\end{array}$ & $\begin{array}{l}\text { Fiber } \\
\text { based }\end{array}$ & Toluene & PDMS & $\begin{array}{l}0.833 \mathrm{~g} \cdot \mathrm{m}^{-3} \text { to } 140.8 \\
\mathrm{~g}-\mathrm{m}^{-3}\end{array}$ & $1.4 \mathrm{~nm} / \mathrm{g}-\mathrm{m}^{-3}$ & $\begin{array}{l}\text { Response time } 5 \mathrm{sec} \\
\text { Recovery time } 40 \mathrm{sec}\end{array}$ & - & [108] \\
\hline 7 & $\begin{array}{l}\text { FP } \\
\text { Interferometer }\end{array}$ & $\begin{array}{l}\text { fiber } \\
\text { based }\end{array}$ & Ethanol and acetone & $\begin{array}{l}\text { Polymethyl methacrylate } \\
\text { (PMMA) film }\end{array}$ & $\begin{array}{l}0 \mathrm{ppm}-1800 \mathrm{ppm} \text { for } \\
\text { Ethanol and acetone }\end{array}$ & $\begin{array}{l}2.7 \mathrm{pm} / \mathrm{ppm} \text { for ethanol and } \\
2.17 \mathrm{pm} / \mathrm{ppm} \text { for acetone }\end{array}$ & NA & $\begin{array}{l}\text { Good selectivity. } \\
\text { Insensitive to inorganic } \\
\text { compounds }\end{array}$ & [109] \\
\hline 8 & $\begin{array}{l}\text { Sagnac } \\
\text { interferometer }\end{array}$ & $\begin{array}{l}\text { Fiber } \\
\text { based }\end{array}$ & Isopropanol & PDMS & 0ppm-6000 ppm & $\begin{array}{l}1.03 \mathrm{pm} / \mathrm{ppm} \\
\text { LOD: } 19.3 \mathrm{ppm}\end{array}$ & $1 \mathrm{~min}$ & - & [110] \\
\hline 9 & $\begin{array}{l}\text { FP } \\
\text { interferometer }\end{array}$ & $\begin{array}{l}\text { Chip- } \\
\text { based } \\
\text { with } \mu \mathrm{GC}\end{array}$ & $\begin{array}{l}\text { Acetone, methanol, } \\
\text { heptane and Toluene }\end{array}$ & $\begin{array}{l}\text { 1. OV-1 (PDMS) } \\
\text { 2. OV-73 } \\
\text { (diphenyldimethylsilicone) } \\
\text { 3. OV-215 } \\
\text { (trifluoropropylmethylsilic } \\
\text { one) } \\
\text { 4. OV-1701 (dimethylphenyl } \\
\text { cyano substituted) }\end{array}$ & $\begin{array}{l}\text { 10ng-100 ng for } \\
\text { methanol. } \\
0.5 \mathrm{ng}-10 \mathrm{ng} \text { for } \\
\text { acetone. } \\
0.1 \mathrm{ng}-1 \mathrm{ng} \text { for } \\
\text { heptane. } \\
0.1 \text { to } 1 \mathrm{ng} \text { for } \\
\text { toluene. (Approx.*) } \\
\end{array}$ & $\begin{array}{l}\text { LOD for toluene, } \\
0.79 \mathrm{pg}(28 \mathrm{ppb}) \text { using OV-1. }\end{array}$ & Sub second & $\begin{array}{l}\text { The interferometer was } \\
\text { employed with } \mu \text {-GC }\end{array}$ & [117] \\
\hline 10 & $\begin{array}{l}\text { FP } \\
\text { interferometer }\end{array}$ & $\begin{array}{l}\text { Chip- } \\
\text { based }\end{array}$ & Toluene and acetone & PDMS and SU-8 & $\begin{array}{l}0-20 \mathrm{ng} \text { for toluene } \\
0-150 \mathrm{ng} \text { for acetone } \\
\text { using PDMS. }\end{array}$ & $\begin{array}{l}2900 \mathrm{uV} / \mathrm{ng}(\text { LOD } 1.7 \mathrm{ppm}) \text { for toluene and } \\
46 \mathrm{uV} / \mathrm{ng} \text { (LOD } 202 \mathrm{ppm}) \text { using PDMS. } \\
4 \mathrm{uV} / \mathrm{ng}(\text { LOD } 2336 \mathrm{ppm} \text { ) for acetone using } \\
\text { SU-8 }\end{array}$ & $\begin{array}{l}0.9 \mathrm{sec} \text { for toluene } \\
0.5 \mathrm{sec} \text { for acetone using } \\
\text { PDMS }\end{array}$ & - & [112] \\
\hline
\end{tabular}




\begin{tabular}{|c|c|c|c|c|c|c|c|c|c|}
\hline 11 & $\begin{array}{l}\text { FP } \\
\text { interferometer }\end{array}$ & $\begin{array}{l}\text { Chip- } \\
\text { based }\end{array}$ & $\begin{array}{l}\text { m-xylene and } \\
\text { cyclohexane }\end{array}$ & PDMS and PDMS-PDPS & $\begin{array}{l}0 \text { ppm- } 3500 \text { ppm for } \\
\text { cyclohexane. } \\
0 \text { ppm- } 1000 \text { ppm for } \\
\text { xylene (Approx.*) }\end{array}$ & $\begin{array}{l}\text { Sensitivity for m-xylene: } 0.0133 \mathrm{~nm} / \mathrm{ppm} \\
\text { (approx.*) } \\
\text { LOD for: } \\
\text { m-Xylene } 1.6 \mathrm{ppm} \\
\text { cyclohexane } 6.3 \mathrm{ppm}\end{array}$ & $\begin{array}{l}40 \mathrm{sec} \text { for cyclohexane. } \\
150 \mathrm{sec} \text { for m-xylene }\end{array}$ & - & [113] \\
\hline 12 & $\begin{array}{l}\text { FP } \\
\text { interferometer }\end{array}$ & $\begin{array}{l}\text { Chip } \\
\text { based }\end{array}$ & Ethanol & $\begin{array}{l}\text { Polychloro-para-xylylene } \\
\text { (Parylene-C) }\end{array}$ & NA & $0.625 \mathrm{~nm} / \mathrm{ppm}$ for ethanol & NA & $\begin{array}{l}\text { LED and Photodiode were } \\
\text { used as a source and } \\
\text { detector }\end{array}$ & [114] \\
\hline 13 & $\begin{array}{l}\text { Spectral } \\
\text { interferometry }\end{array}$ & $\begin{array}{l}\text { Fiber- } \\
\text { based }\end{array}$ & $\begin{array}{l}\text { Pentane, hexane, } \\
\text { heptane, octane, } \\
\text { chloroform, } \\
\text { tricholormethyl, } \\
\text { trichloroethane, } \\
\text { Tetrachloroethene } \\
\text { (TCE), } \\
\text { Dichrolomethane }\end{array}$ & $\begin{array}{l}\text { Polysiloxane, } \\
\text { dimethylpolysiloxane } \\
\text { (DMPS) }\end{array}$ & $\begin{array}{l}1000 \mathrm{ppm} \text { for } \\
\text { heptane. } \\
10^{4} \mathrm{ppm} \text { for } \\
\text { perfluroethylene. } \\
2600 \mathrm{ppm} \text { for TCE }\end{array}$ & 100ppm (Approx.) & Less than one sec & $\begin{array}{l}\text { The sensor was also test } \\
\text { tested for dynamic } \\
\text { observation of immune } \\
\text { reactions. The } \\
\text { multicomponent analysis } \\
\text { was performed using a } \\
\text { combination of different } \\
\text { polymers }\end{array}$ & [115] \\
\hline 14 & $\begin{array}{l}\text { Pohl } \\
\text { Interferometer }\end{array}$ & $\begin{array}{l}\text { Open } \\
\text { space }\end{array}$ & $\begin{array}{l}\text { Alcohol (Methanol, } \\
\text { ethanol, propanol), } \\
\text { ethers (methyl } \\
\text { acetate, propyl } \\
\text { acetate) and alkanes } \\
\text { (heptane, octane) }\end{array}$ & PDMS & 0 ppm-24000 ppm & $\begin{array}{l}<0.02 \mathrm{nW} / \mathrm{ppm} \text { for methanol, ethanol, } \\
\text { propanol and methyl Acetate. } \\
0.14 \mathrm{nW} / \mathrm{ppm} \text { for Propyl Acetate } \\
0.05 \mathrm{nW} / \mathrm{ppm} \text { for heptane } \\
0.12 \mathrm{nW} / \mathrm{ppm} \text { for Octane }\end{array}$ & $\begin{array}{l}\text { Initial response is fast for } 240 \\
\text { sec approx. }\end{array}$ & $\begin{array}{l}\text { The details of the PDMS } \\
\text { variation and its correlation } \\
\text { with the BTEX molecules } \\
\text { is not available. } \\
\text { Limitations of the sensor } \\
\text { are explained. }\end{array}$ & [83] \\
\hline 15 & $\begin{array}{l}\text { Michelson } \\
\text { interferometer }\end{array}$ & $\begin{array}{l}\text { Open } \\
\text { space }\end{array}$ & Benzene and ethanol & No sensing film was used & $\begin{array}{l}1611 \mathrm{ppm}-32210 \\
\text { ppm and } 964 \mathrm{ppm}- \\
19290 \mathrm{ppm} \text { was } \\
\text { found for ethanol } \\
\text { and benzene, } \\
\text { respectively. }\end{array}$ & $\begin{array}{l}0.006 \mathrm{pixels} / \mathrm{ppm} \text { for ethanol and } 0.015 \\
\text { pixels/ppm for benzene. }\end{array}$ & NA & $\begin{array}{l}\text { No sensing film was } \\
\text { employed. }\end{array}$ & [116] \\
\hline
\end{tabular}


[1] US EPA, "Technical overview of volatile organic compounds," United States Environmental Protection Agency, 2018. [Online]. Available: https://www.epa.gov/indoor-air-qualityiaq/technical-overview-volatile-organic-compounds. [Accessed: 23-Mar-2017].

[2] The European Parliament and the Council of the European Union, "Directive 2004/42/CE of the European Parliament and of the Council of 21 April 2004 on the limitation of emissions of volatile organic compounds due to the use of organic solvents in certain paints and varnishes and vehicle refinishing products and amendi," Off. J. Eur. Unio, vol. 143, no. L 143, pp. 87-96, 2004.

[3] R. Koppmann, "Chemistry of Volatile Organic Compounds in the Atmosphere," in Handbook of Hydrocarbon and Lipid Microbiology, Berlin, Heidelberg: Springer Berlin Heidelberg, 2010, pp. 267-277.

[4] F. I. Khan and A. Kr. Ghoshal, "Removal of Volatile Organic Compounds from polluted air," J. Loss Prev. Process Ind., vol. 13, no. 6, pp. 527-545, Nov. 2000.

[5] E. Gallego, F. X. Roca, X. Guardino, and M. G. Rosell, "Indoor and outdoor BTX levels in Barcelona City metropolitan area and Catalan rural areas," J. Environ. Sci., vol. 20, no. 9, pp. 1063-1069, Jan. 2008.

[6] G. A. Pilidis, S. P. Karakitsios, and P. A. Kassomenos, "BTX measurements in a medium-sized European city," Atmos. Environ., vol. 39, no. 33, pp. 6051-6065, Oct. 2005.

[7] X. Zhang, B. Gao, A. E. Creamer, C. Cao, and Y. Li, “Adsorption of VOCs onto engineered carbon materials: A review," J. Hazard. Mater., vol. 338, pp. 102-123, Sep. 2017.

[8] P. Schneider et al., "Indoor and outdoor BTX levels in German cities," Sci. Total Environ., vol. 267, no. 1-3, pp. 41-51, Feb. 2001.

[9] L. A. Wallace, "Major sources of benzene exposure," Environ. Health Perspect., vol. 82, pp. 165-169, 1989.

[10] E. Ilgen et al., "Aromatic hydrocarbons in the atmospheric environment: Part I. Indoor versus outdoor sources, the influence of traffic," Atmos. Environ., vol. 35, no. 7, pp. 1235-1252, Jan. 2001.

[11] G. A. Ayoko, "Volatile Organic Compounds in Indoor Environments," in Environmental Chemistry, vol. 4, 2004, pp. 1-35.

[12] K. Kawamura, M. Vestergaard, M. Ishiyama, N. Nagatani, T. Hashiba, and E. Tamiya, "Development of a novel hand-held toluene gas sensor: Possible use in the prevention and control of sick building syndrome," Measurement, vol. 39, no. 6, pp. 490-496, Jul. 2006. 
[13] WHO, "Exposure to Benzene: A Major public health concern," 2010.

[14] R. Baan et al., "A review of human carcinogens--Part F: chemical agents and related occupations.," Lancet. Oncol., vol. 10, no. 12, pp. 1143-4, Dec. 2009.

[15] "Benzene (IARC Summary \&amp; Evaluation, Supplement7, 1987)." [Online]. Available: http://www.inchem.org/documents/iarc/suppl7/benzene.html. [Accessed: 26-Mar-2017].

[16] D. Pyatt and S. Hays, "A review of the potential association between childhood leukemia and benzene," Chemico-Biological Interactions, vol. 184, no. 1-2. pp. 151-164, 19-Mar-2010.

[17] P. Patnaik, A comprehensive guide to the hazardous properties of chemical substances. John Wiley, 2007.

[18] R. Kandyala, S. P. Raghavendra, and S. Rajasekharan, "Xylene: An overview of its health hazards and preventive measures," J. Oral Maxillofac. Pathol., vol. 14, no. 1, p. 1, Jan. 2010.

[19] W. J. Kim et al., "Effect of formaldehyde on the expression of adhesion molecules in nasal microvascular endothelial cells: The role of formaldehyde in the pathogenesis of sick building syndrome," Clin. Exp. Allergy, vol. 32, no. 2, pp. 287-295, Feb. 2002.

[20] I. Castro-Hurtado, G. G. Mandayo, and E. Castaño, "Conductometric formaldehyde gas sensors. A review: From conventional films to nanostructured materials," Thin Solid Films, vol. 548, pp. 665-676, Dec. 2013.

[21] O. Bunkoed, F. Davis, P. Kanatharana, P. Thavarungkul, and S. P. J. Higson, "Sol-gel based sensor for selective formaldehyde determination," Anal. Chim. Acta, vol. 659, no. 1-2, pp. 251257, Feb. 2010.

[22] EU, "Directive 2008/50/EC of the European Parliament and of the Council of 21 May 2008 on ambient air quality and cleaner air for Europe," 2008.

[23] M. . Barson, "NIOSH-Pocket Guide to Chemical Hazards,” Pittsburgh USA, 2005.

[24] L. Spinelle, M. Gerboles, G. Kok, S. Persijn, and T. Sauerwald, "Review of Portable and LowCost Sensors for the Ambient Air Monitoring of Benzene and Other Volatile Organic Compounds," Sensors, vol. 17, no. 7, p. 1520, Jun. 2017.

[25] P. K. Sekhar and K. Subramaniyam, "Detection of Harmful Benzene, Toluene, Ethylbenzene, Xylenes (BTEX) Vapors Using Electrochemical Gas Sensors,” ECS Electrochem. Lett., vol. 3, no. 2, pp. B1-B4, 2014.

[26] F. Haghighi, Z. Talebpour, and A. Sanati-Nezhad, "Through the years with on-a-chip gas chromatography: a review," Lab Chip, vol. 15, no. 12, pp. 2559-2575, 2015. 
[27] H. Zhu et al., "Flow-through microfluidic photoionization detectors for rapid and highly sensitive vapor detection," Lab Chip, vol. 15, no. 14, pp. 3021-3029, 2015.

[28] A. Kumar, J. Brunet, C. Varenne, A. Ndiaye, and A. Pauly, "Phthalocyanines based QCM sensors for aromatic hydrocarbons monitoring: Role of metal atoms and substituents on response to toluene," Sensors Actuators, B Chem., vol. 230, pp. 320-329, Jul. 2016.

[29] C. Chen et al., "A new sensor for the assessment of personal exposure to volatile organic compounds," Atmos. Environ., vol. 54, pp. 679-687, 2012.

[30] S. Fanget et al., "Gas sensors based on gravimetric detection - A review," Sensors Actuators, B Chem., vol. 160, no. 1, pp. 804-821, 2011.

[31] A. Mirzaei, J. H. Kim, H. W. Kim, and S. S. Kim, "Resistive-based gas sensors for detection of benzene, toluene and xylene (BTX) gases: A review,” Royal Society of Chemistry, 2018.

[32] J. R. Askim, M. Mahmoudi, and K. S. Suslick, "Optical sensor arrays for chemical sensing: the optoelectronic nose.," Chem. Soc. Rev., vol. 42, no. 22, pp. 8649-8682, 2013.

[33] A. Allouch, S. Le Calvé, and C. A. Serra, "Portable, miniature, fast and high sensitive real-time analyzers: BTEX detection," Sensors Actuators, B Chem., vol. 182, pp. 446-452, 2013.

[34] J. Hodgkinson and R. P. Tatam, "Optical gas sensing: a review," Meas. Sci. Technol., vol. 24, no. 1, p. 012004, 2013.

[35] C. McDonagh, C. S. Burke, and B. D. MacCraith, "Optical chemical sensors," Chem. Rev., vol. 108, no. 2, pp. 400-422, 2008.

[36] H. Qazi, a Mohammad, and M. Akram, "Recent Progress in Optical Chemical Sensors," Sensors, vol. 12, no. 12, pp. 16522-16556, 2012.

[37] B. H. Bunch and A. Hellemans, The history of science and technology. Houghton Mifflin, 2004.

[38] P. Hariharan, Basics of Interferometry. Elsevier, 2007.

[39] M. Hirsch et al., "Low-Coherence Interferometric Fiber-Optic Sensors with Potential Applications as Biosensors,” Sensors, vol. 17, no. 2, p. 261, Jan. 2017.

[40] K. Riles, "Recent searches for continuous gravitational waves," Mod. Phys. Lett. A, vol. 32, no. 39, p. 1730035, Dec. 2017.

[41] P. Shore and P. Morantz, "Ultra-precision: enabling our future.," Philos. Trans. A. Math. Phys. Eng. Sci., vol. 370, no. 1973, pp. 3993-4014, Aug. 2012.

[42] C. Zuo, S. Feng, L. Huang, T. Tao, W. Yin, and Q. Chen, "Phase shifting algorithms for fringe 
projection profilometry: A review," Opt. Lasers Eng., vol. 109, pp. 23-59, Oct. 2018.

[43] K. G. Libbrecht and E. D. Black, "A basic Michelson laser interferometer for the undergraduate teaching laboratory demonstrating picometer sensitivity," Am. J. Phys., vol. 83, no. 5, pp. 409417, May 2015.

[44] J. Lawall and E. Kessler, "Michelson interferometry with $10 \mathrm{pm}$ accuracy," Rev. Sci. Instrum., vol. 71, no. 7, p. 2669, Jun. 2000.

[45] J. Garvey, D. Newport, A. Fereydoun, L. Ae, M. Whelan, and S. Joseph, "Full field measurement at the micro-scale using micro-interferometry," 2007.

[46] D. Newport, C. B. Sobhan, and J. Garvey, "Digital interferometry: techniques and trends for fluid measurement," Heat Mass Transf., vol. 44, no. 5, pp. 535-546, Mar. 2008.

[47] T. Hubert, L. Boon-Brett, G. Black, and U. Banach, "Hydrogen sensors - A review," Sensors Actuators, B Chem., vol. 157, no. 2, pp. 329-352, 2011.

[48] R. Bommareddi, "Applications of Optical Interferometer Techniques for Precision Measurements of Changes in Temperature, Growth and Refractive Index of Materials," Technologies, vol. 2, no. 2, pp. 54-75, 2014.

[49] Q. Zhang, S. Zhong, J. Zhong, and X. Fu, "Ultrahigh-accuracy measurement of refractive index curves of optical materials using interferometry technology," Measurement, vol. 122, pp. 40-44, Jul. 2018.

[50] Y. Wang, M. Sun, Y. Cao, and J. Zhu, "Application of optical interferometry in focused acoustic field measurement," J. Sound Vib., vol. 426, pp. 234-243, Jul. 2018.

[51] Y. Wang, F. Xie, S. Ma, and L. Dong, "Review of surface profile measurement techniques based on optical interferometry," Opt. Lasers Eng., vol. 93, pp. 164-170, Jun. 2017.

[52] A. Aizen, M. Ney, A. Safrani, and I. Abdulhalim, "A compact real-time high-speed highresolution vibrometer, surface profiler and dynamic focus tracker using three wavelengths parallel phase-shift interferometry," Opt. Lasers Eng., vol. 107, pp. 304-314, Aug. 2018.

[53] E. Makarona, P. Petrou, S. Kakabakos, K. Misiakos, and I. Raptis, "Point-of-Need bioanalytics based on planar optical interferometry," Biotechnol. Adv., vol. 34, no. 3, pp. 209-233, May 2016.

[54] K.-H. Chen, C.-C. Hsu, and D.-C. Su, "Interferometric optical sensor for measuring glucose concentration," Appl. Opt., vol. 42, no. 28, p. 5774, Oct. 2003.

[55] W. Merzkirch, Flow visualization. Academic Press, 1987.

[56] S. Yin, P. B. Ruffin, and F. T. S. Yu, Fiber Optic Sensors, vol. 21. New York: Marcel Dekker 
Inc., 2017.

[57] Y. Huang, J. Tao, X. Huang, Y. W. Huang, J. Tao, and X. G. Huang, "Research Progress on FP Interference-Based Fiber-Optic Sensors," Sensors, vol. 16, no. 9, p. 1424, Sep. 2016.

[58] I. Paper, "Fiber Optic Smart Structures," vol. 84, p. 671, 1996.

[59] H. Y. Fu et al., "Pressure sensor realized with polarization-maintaining photonic crystal fiberbased Sagnac interferometer," Appl. Opt., vol. 47, no. 15, p. 2835, 2008.

[60] L.-Y. Shao et al., "Optical Fiber Temperature and Torsion Sensor Based on Lyot-Sagnac Interferometer," Sensors, vol. 16, no. 10, p. 1774, Oct. 2016.

[61] J. Ascorbe, J. Corres, F. Arregui, and I. Matias, "Recent Developments in Fiber Optics Humidity Sensors," Sensors, vol. 17, no. 4, p. 893, Apr. 2017.

[62] B. Gu, W. Yuan, S. He, and O. Bang, "Temperature compensated strain sensor based on cascaded sagnac interferometers and all-solid birefringent hybrid photonic crystal fibers," IEEE Sens. J., vol. 12, no. 6, pp. 1641-1646, 2012.

[63] J. Zhang et al., "Highly-Sensitive Temperature Sensor Using a Hi-Bi Fiber Tip Probe," IEEE Sens. J., vol. 12, no. 6, pp. 2077-2080, Jun. 2012.

[64] B. Xu et al., "Sagnac interferometer hydrogen sensor based on panda fiber with Pt-loaded WO_3/SiO_2 coating," Opt. Lett., vol. 41, no. 7, p. 1594, Apr. 2016.

[65] Zehnder L, "Ein neuer interferenzrefraktor.," Zeitschrift fur Instrumentenkd., vol. 11, pp. 275$285,1891$.

[66] M. L, "Uber einen interferenzrefraktor," Zeitschrift fur Instrumentenkd., vol. 12, pp. 89-93, 1892.

[67] M. Faryad, A. Lakhtakia, and P. V Lambeck, "Measurement Science and Technology Integrated optical sensors for the chemical domain Recent citations Cuma Tyszkiewicz et al-Przemyslaw Struk et al-Integrated optical sensors for the chemical domain," Meas. Sci. Technol, vol. 17, pp. 93-116, 2006.

[68] B. Baby and B. Anooplal, "Measurement of Temperature Distribution around a Vertical Fin by Mach-zehnder Interferometry,” Procedia Technol., vol. 25, pp. 1265-1272, Jan. 2016.

[69] Y. Liu, W. Peng, Y. Liang, X. Zhang, X. Zhou, and L. Pan, "Fiber-optic Mach-Zehnder interferometric sensor for high-sensitivity high temperature measurement," Opt. Commun., vol. 300, pp. 194-198, Jul. 2013.

[70] G. Statkiewicz-Barabach et al., "Hydrostatic Pressure and Temperature Measurements Using an 
In-Line Mach-Zehnder Interferometer Based on a Two-Mode Highly Birefringent Microstructured Fiber," Sensors, vol. 17, no. 7, p. 1648, Jul. 2017.

[71] D. T. Van-Pham, K. Sorioka, T. Norisuye, and Q. Tran-Cong-Miyata, "Formation and relaxation of the elastic strain generated by photocuring in polymer blends monitored by Mach-Zehnder interferometry," Polymer (Guildf)., vol. 52, no. 3, pp. 739-745, Feb. 2011.

[72] A. Abdallah, "Experimental study on an interferometric strain sensor based on hollow-core photonic bandgap fiber for intrusion detection," Opt. Commun., vol. 428, pp. 35-40, Dec. 2018.

[73] O. T. Kamenev, Y. N. Kulchin, Y. S. Petrov, R. V. Khiznyak, and R. V. Romashko, "Fiber-optic seismometer on the basis of Mach-Zehnder interferometer," Sensors Actuators A Phys., vol. 244, pp. 133-137, Jun. 2016.

[74] X. Liu et al., "Distributed Fiber-Optic Sensors for Vibration Detection," Sensors, vol. 16, no. 8, p. 1164 , Jul. 2016.

[75] A. Kumar and N. Kumar, "Simultaneous measurement of current and temperature by using an all-fiber interferometric cost-effective and non-destructive sensing scheme," Optik (Stuttg)., vol. 171, pp. 1-8, Oct. 2018.

[76] Y. Luo, X. Lei, F. Shi, and B. Peng, "A novel optical fiber magnetic field sensor based on MachZehnder interferometer integrated with magnetic fluid," Optik (Stuttg)., vol. 174, pp. 252-258, Dec. 2018.

[77] Y. Qian, Y. Zhao, Q. lu Wu, and Y. Yang, "Review of salinity measurement technology based on optical fiber sensor," Sensors and Actuators, B: Chemical, vol. 260. Elsevier, pp. 86-105, 01May-2018.

[78] A. Bastos et al., "Integrated Optical Mach-Zehnder Interferometer Based on Organic-Inorganic Hybrids for Photonics-on-a-Chip Biosensing Applications," Sensors, vol. 18, no. 3, p. 840, Mar. 2018.

[79] S. Barthwal and A. Vudayagiri, "Construction of an inexpensive molecular iodine spectrometer using a self-developed Pohl wavemeter around 670 nm wavelength," Eur. J. Phys., vol. 36, no. 5, p. 055014, Sep. 2015.

[80] J. L. Gresty, “Optical Shop Testing,” Opt. Acta Int. J. Opt., vol. 26, no. 7, pp. 836-836, 1979.

[81] D. E. Ewbank, "Single Arm Interferometer System for Reflective Micro-Device Phase Measurement," in International Optical Design Conference and Optical Fabrication and Testing, 2010, p. OWC2.

[82] J. H. Wasilik, T. V. Blomquist, and C. S. Willett, "Measurement of Parallelism of the Surfaces 
of a Transparent Sample Using Two-Beam Nonlocalized Fringes Produced by a Laser," Appl. Opt., vol. 10, no. 9, p. 2107, Sep. 1971.

[83] C. Martínez-Hipatl, S. Muñoz-Aguirre, G. Beltrán-Pérez, J. Castillo-Mixcóatl, and J. Rivera-De la Rosa, "Detection of volatile organic compounds by an interferometric sensor," Sensors Actuators, B Chem., vol. 147, no. 1, pp. 37-42, 2010.

[84] G. M. Whitesides, E. Ostuni, S. Takayama, X. Jiang, and D. E. Ingber, "Soft Lithography in Biology and Biochemistry," Annu. Rev. Biomed. Eng., vol. 3, no. 1, pp. 335-373, Aug. 2001.

[85] N. Bhattacharjee, A. Urrios, S. Kang, and A. Folch, "The upcoming 3D-printing revolution in microfluidics," Lab Chip, vol. 16, no. 10, pp. 1720-1742, May 2016.

[86] J. L. Wilbur, R. J. Jackman, G. M. Whitesides, E. L. Cheung, L. K. Lee, and M. G. Prentiss, “Elastomeric optics," Chem. Mater., vol. 8, no. 7, pp. 1380-1385, 1996.

[87] S. K. Sia and G. M. Whitesides, "Microfluidic devices fabricated in Poly(dimethylsiloxane) for biological studies," Electrophoresis, vol. 24, no. 21, pp. 3563-3576, Nov. 2003.

[88] S. J. Clarson and J. A. Semlyen, Siloxane polymers. Prentice Hall, 1993.

[89] R. St-Gelais et al., "A Fabry-Perot refractometer for chemical vapor sensing by solid-phase microextraction," in 16th International Conference on Optical MEMS and Nanophotonics, 2011, pp. $85-86$.

[90] R. Howley, B. D. MacCraith, K. O’Dwyer, H. Masterson, P. Kirwan, and P. McLoughlin, "Determination of Hydrocarbons Using Sapphire Fibers Coated with Poly(Dimethylsiloxane)," Appl. Spectrosc., vol. 57, no. 4, pp. 400-406, Apr. 2003.

[91] J. Zhang, J. Dong, M. Luo, H. Xiao, S. Murad, and R. A. Normann, "Zeolite-Fiber Integrated Optical Chemical Sensors for Detection of Dissolved Organics in Water," Langmuir, vol. 21, no. 19, pp. 8609-8612, Sep. 2005.

[92] T. C. Bowen, R. D. Noble, and J. L. Falconer, "Fundamentals and applications of pervaporation through zeolite membranes," J. Memb. Sci., vol. 245, no. 1-2, pp. 1-33, Dec. 2004.

[93] O. Hugon, M. Sauvan, P. Benech, C. Pijolat, and F. Lefebvre, "Gas separation with a zeolite filter, application to the selectivity enhancement of chemical sensors," Sensors Actuators B Chem., vol. 67, no. 3, pp. 235-243, Sep. 2000.

[94] A. Walcarius, "Zeolite-modified electrodes in electroanalytical chemistry," Anal. Chim. Acta, vol. 384, no. 1, pp. 1-16, Mar. 1999.

[95] K. T. Thomson, "Handbook of Zeolite Science and Technology Edited by Scott M. Auerbach 
(University of Massachusetts, Amherst), Kathleen A. Carrado (Argonne National Laboratory), Prabir K. Dutta (The Ohio State University). Marcel Dekker, Inc.: New York, Basel. 2003. xii,” J. Am. Chem. Soc., vol. 126, no. 28, pp. 8858-8859, 2004.

[96] B. Wu, C. Zhao, J. Kang, and D. Wang, "Characteristic study on volatile organic compounds optical fiber sensor with zeolite thin film-coated spherical end," Opt. Fiber Technol., vol. 34, pp. 91-97, 2017.

[97] H. Su and X. G. Huang, "Fresnel-reflection-based fiber sensor for on-line measurement of solute concentration in solutions," Sensors Actuators B Chem., vol. 126, no. 2, pp. 579-582, Oct. 2007.

[98] W. Ma et al., "CO2 Gas Sensing Using Optical Fiber Fabry-Perot Interferometer Based on Polyethyleneimine/Poly(Vinyl Alcohol) Coating,” IEEE Photonics J., vol. 9, no. 3, pp. 1-8, Jun. 2017.

[99] T. Hao and K. S. Chiang, "Graphene-Based Ammonia-Gas Sensor Using In-Fiber Mach-Zehnder Interferometer," IEEE Photonics Technol. Lett., vol. 29, no. 23, pp. 2035-2038, Dec. 2017.

[100] A. W. Raymond, B. J. Drouin, A. Tang, E. Schlecht, and E. Mazur, "Miniature cavity for in situ millimeter wave gas sensing: N2O and CH3OH detection," Sensors Actuators B Chem., vol. 254, pp. 763-770, Jan. 2018.

[101] D. Deng, W. Feng, J. Wei, X. Qin, and R. Chen, "Trace hydrogen sulfide gas sensor based on tungsten sulfide membrane-coated thin-core fiber modal interferometer," Appl. Surf. Sci., vol. 423, pp. 492-497, Nov. 2017.

[102] J. Liu, Y. Sun, and X. Fan, "Highly versatile fiber-based optical Fabry-Pérot gas sensor.," Opt. Express, vol. 17, no. 4, pp. 2731-2738, 2009.

[103] J. Liu et al., "Fabry-Pérot cavity sensors for multipoint on-column micro gas chromatography detection," Anal. Chem., vol. 82, no. 11, pp. 4370-4375, Jun. 2010.

[104] X. Ning, J. Yang, C. L. Zhao, and C. C. Chan, "PDMS-coated fiber volatile organic compounds sensors," Appl. Opt., vol. 55, no. 13, p. 3543, May 2016.

[105] X. Ning, C. L. Zhao, J. Yang, and C. C. Chan, "Zeolite thin film-coated spherical end-face fiber sensors for detection of trace organic vapors," Opt. Commun., vol. 364, pp. 55-59, 2016.

[106] B. Wu, C. Zhao, J. Kang, and D. Wang, "Characteristic study on volatile organic compounds optical fiber sensor with zeolite thin film-coated spherical end," Opt. Fiber Technol., vol. 34, pp. 91-97, 2017.

[107] I. Martincek and D. Kacik, "A PDMS microfiber Mach-Zehnder interferometer and determination of nanometer displacements," Opt. Fiber Technol., vol. 40, pp. 13-17, 2018. 
[108] D. Kacik and I. Martincek, "Toluene optical fibre sensor based on air microcavity in PDMS," Opt. Fiber Technol., vol. 34, pp. 70-73, Mar. 2017.

[109] C.-B. Yu et al., "Highly sensitive and selective fiber-optic Fabry-Perot volatile organic compounds sensor based on a PMMA film," Opt. Mater. Express, vol. 7, no. 6, pp. 1872-1874, 2017.

[110] B.-Q. Wu, C.-L. Zhao, and Z.-M. Ding, "Sagnac interferometer fiber volatile organic compounds sensor based on PDMS," Guangzi Xuebao/Acta Photonica Sin., vol. 46, no. 1, p. 106003, 2017.

[111] K. Reddy, Y. Guo, J. Liu, W. Lee, M. K. K. Oo, and X. Fan, "Rapid, sensitive, and multiplexed on-chip optical sensors for micro-gas chromatography," Lab Chip, vol. 12, no. 5, pp. 901-905, 2012.

[112] K. Reddy, Y. Guo, J. Liu, W. Lee, M. K. Khaing Oo, and X. Fan, “On-chip Fabry-Pérot interferometric sensors for micro-gas chromatography detection," Sensors Actuators B Chem., vol. 159, no. 1, pp. 60-65, Nov. 2011.

[113] R. St-Gelais et al., "Gas sensing using polymer-functionalized deformable Fabry-Perot interferometers," Sensors Actuators, B Chem., vol. 182, pp. 45-52, 2013.

[114] S. Maruyama, T. Hizawa, K. Takahashi, and K. Sawada, "Optical-interferometry-based CMOSMEMS sensor transduced by stress-induced nanomechanical deflection," Sensors (Switzerland), vol. 18, no. 1, p. 138, Jan. 2018.

[115] G. Gauglitz, A. Brecht, G. Kraus, and W. Mahm, "Chemical and biochemical sensors based on interferometry at thin (multi-) layers," Sensors Actuators B. Chem., vol. 11, no. 1-3, pp. 21-27, 1993.

[116] Marzuarman, M. Rivai, T. A. Sardjono, and D. Purwanto, "Investigation of michelson interferometer for volatile organic compound sensor," in Journal of Physics: Conference Series, 2017, vol. 853, no. 1, p. 012017.

[117] K. Reddy, Y. Guo, J. Liu, W. Lee, M. K. Khaing Oo, and X. Fan, "Rapid, sensitive, and multiplexed on-chip optical sensors for micro-gas chromatography," Lab Chip, vol. 12, p. 901, 2012.

[118] Y. Liu, Y.-P. Chen, H. Song, and G. Zhang, "Characteristics of an Optical Fiber Hydrogen Gas Sensor Based on a Palladium and Yttrium Alloy Thin Film," IEEE Sens. J., vol. 13, no. 7, pp. 2699-2704, Jul. 2013.

[119] S. Wang, A. Kallur, and A. Goshu, "Fabrication and characterization of PDMS thin film," 2011, vol. 7935 , p. 79350M. 
[120] Perry A. Martos, and Angela Saraullo, and J. Pawliszyn*, "Estimation of Air/Coating Distribution Coefficients for Solid Phase Microextraction Using Retention Indexes from Linear Temperature-Programmed Capillary Gas Chromatography. Application to the Sampling and Analysis of Total Petroleum Hydrocarbons in Air," 1997.

[121] S. Seethapathy and T. Górecki, "Applications of polydimethylsiloxane in analytical chemistry: A review," Anal. Chim. Acta, vol. 750, pp. 48-62, 2012.

[122] J. Garvey, D. Newport, F. Lakestani, M. Whelan, and S. Joseph, "Full field measurement at the micro-scale using micro-interferometry," Microfluid. Nanofluidics, vol. 5, no. 1, pp. 77-87, 2008

[123] O. Kafri, "Fundamental limit on accuracy in interferometry," Opt. Lett., vol. 14, no. 13, pp. 6578, Jul. 1989.

[124] D. Malacara, M. Servín, and Z. Malacara, Interferogram Analysis For Optical Testing, 2nd Ed. 2005.

[125] S. Khan, D. Newport, and S. Le Calvé, "Study on Absorption of VOCs into PDMS Film using Heterodyne Interferometry for Application of VOCs," in 17th International Meeting on Chemical Sensors - IMCS 2018, 2018, pp. 637-638.

[126] Y.-C. Hsieh and D.-J. Yao, "Intelligent gas-sensing systems and their applications," $J$. Micromechanics Microengineering, vol. 28, no. 9, p. 093001, Sep. 2018.

[127] Z. Chen, Y. Zheng, K. Chen, H. Li, and J. Jian, "Concentration Estimator of Mixed VOC Gases Using Sensor Array with Neural Networks and Decision Tree Learning," IEEE Sens. J., vol. 17, no. 6, pp. 1884-1892, Mar. 2017.

[128] Y. Zhang, Y. Zhao, and Q. Wang, "Multi-component gas sensing based on slotted photonic crystal waveguide with liquid infiltration," Sensors Actuators B Chem., vol. 184, pp. 179-188, Jul. 2013.

[129] R. Del and N. Cimento, "Whispering gallery mode microresonators: Fundamentals and applications," vol. 34, 2011.

[130] M. Quan, J. Tian, and Y. Yao, "Ultra-high sensitivity Fabry-Perot interferometer gas refractive index fiber sensor based on photonic crystal fiber and Vernier effect," Opt. Lett., vol. 40, no. 21, p. 4891, Nov. 2015.

[131] N. Iswarya, M. G. Kumar, K. S. Rajan, and J. B. B. Rayappan, "Metal Organic Framework (MOF-5) For Sensing of Volatile Organic Compounds," J. Appl. Sci., vol. 12, no. 16, pp. 16811685, Dec. 2012. 
[132] K.-J. Kim, P. Lu, J. T. Culp, and P. R. Ohodnicki, "Metal-Organic Framework Thin Film Coated Optical Fiber Sensors: A Novel Waveguide-Based Chemical Sensing Platform," ACS Sensors, vol. 3, no. 2, pp. 386-394, Feb. 2018.

[133] D. Lopez-Torres et al., "Enhancement of the Sensitivity of a Volatile Organic Compounds MOFSensor by Means of Its Structure,” Proceedings, vol. 1, no. 4, p. 451, Aug. 2017. 